
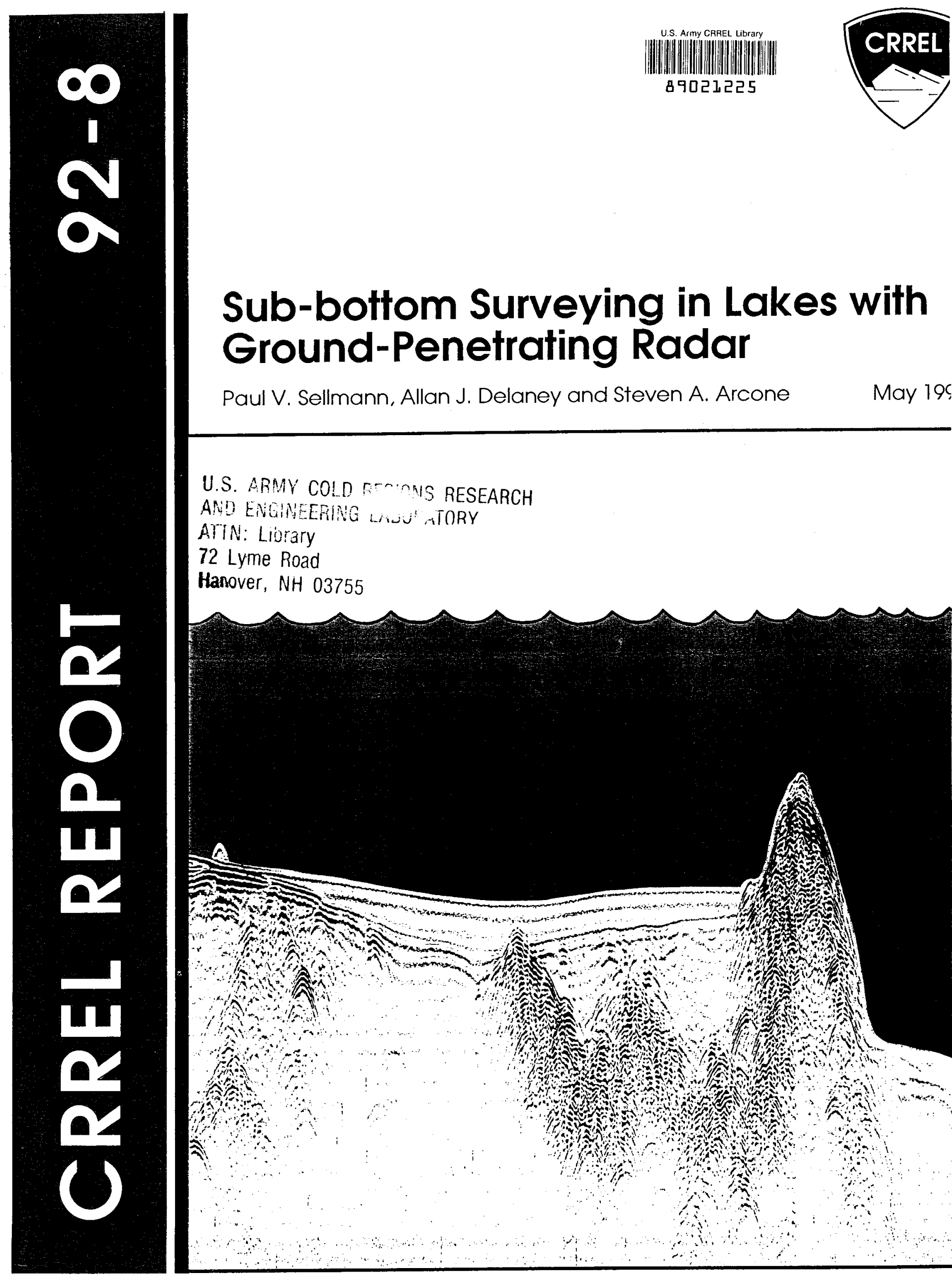

\title{
Sub-bottom Surveying in Lakes with Ground-Penetrating Radar
}

Paul V. Sellmann, Allan J. Delaney and Steven A. Arcone

May 19

U.S. ARMY COLD R-M ONS RESEARCH

ARD ENGINEERING WUU" TORY

ATIN: Liorary

72 Lyme Road

Hanover, NH 03755

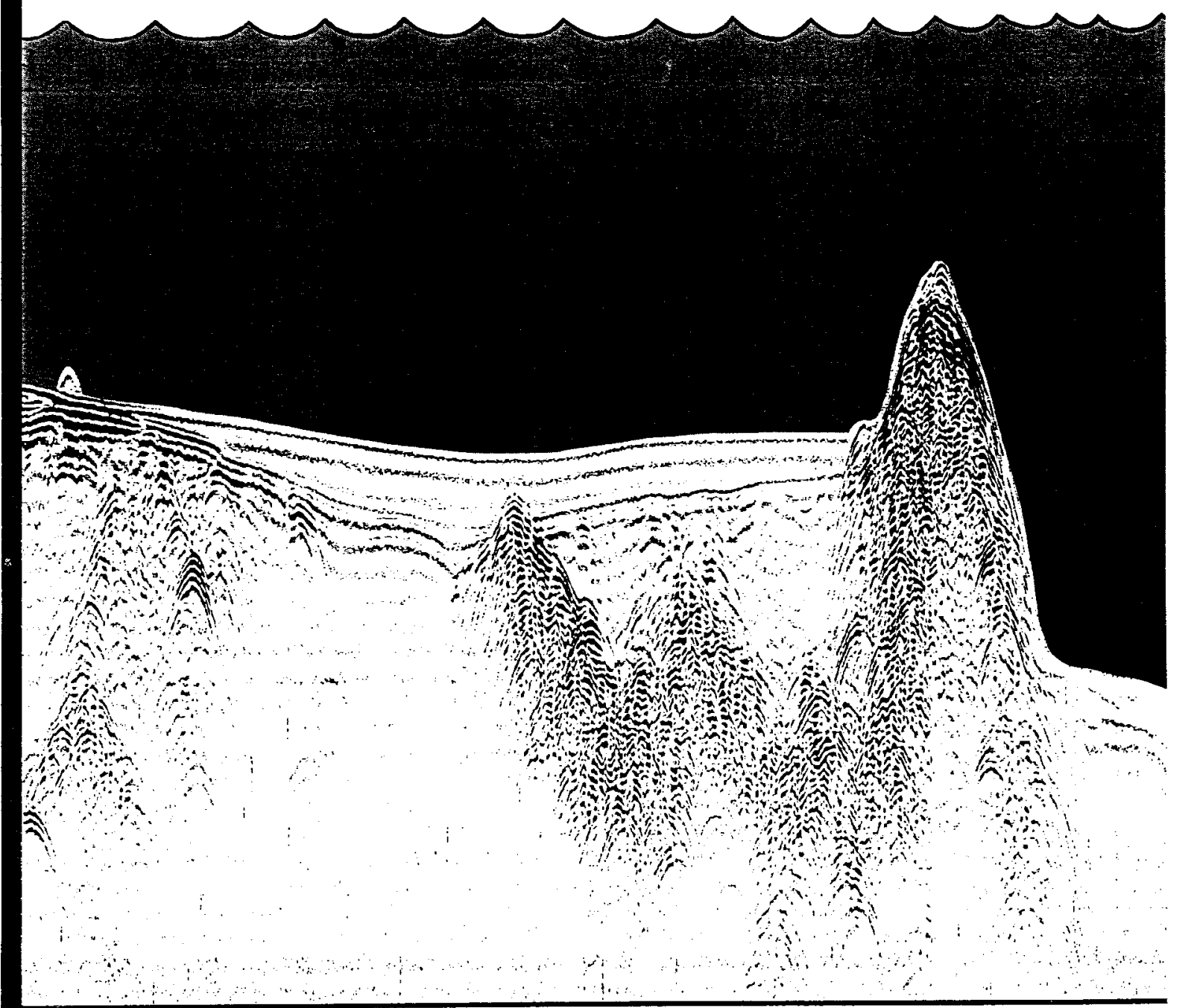




\section{CRREL Report 92-8}

\section{Sub-bottom Surveying in Lakes with Ground-Penetrating Radar}

Paul V. Sellmann, Allan J. Delaney and Steven A. Arcone

May 199\% 


\section{PREFACE}

This report was prepared by Paul V. Sellmann, Geologist, Civil and Geotechnical Engineering Research Branch, Experimental Engineering Division, Allan J. Delaney, Physical Science Technician, and Dr. Steven A. Arcone, Geophysicist, Snow and Ice Branch, Research Division, U.S. Army Cold Regions Research and Engineering Laboratory. Funding for this research was provided by several sources: DA Project 4A161102AT24, Research in Snow, Ice and Frozen Ground, Task SS, Properties of Cold Regions Materials, Work Unit 014, Electromagnetic and Radiative Characteristics of Snow, Ice and Frozen Ground; DA Project 4A762784AT42, Cold Regions Engineering Technology, Task BS, Design of Facilities in Cold Regions, Work Unit 011, Development of Electro-Magnetic Subsurface Explorations System for Cold Regions; CRREL's In-House Laboratory Independent Research Program, Sub-bottom Observations Using Acoustic-Radar Techniques; and CWIS 32795, Surveying and Mapping Program, Sub-bottom Profiling with a Radar System.

Technical review was provided by Dr. James R. Rossiter and J. Les Davis, both of Canpolar, Inc., Toronto, Ontario, Canada.

The contents of this report are not to be used for advertising or promotional purposes. Citation of brand names does not constitute an official endorsement or approval of the use of such commercial products. 


\section{CONTENTS}

Preface

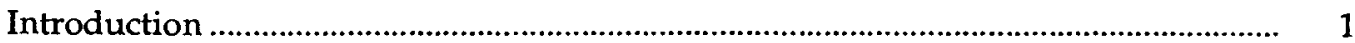

Radar equipment ................................................................................................................. 2

General operation ….................................................................................................... 2

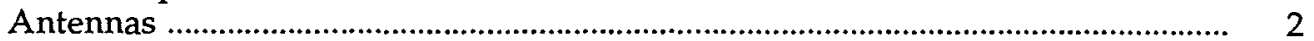

Data processing, display and interpretation ............................................................ 5

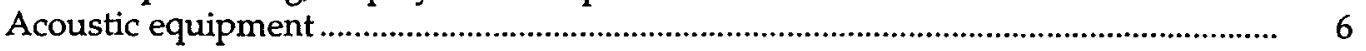

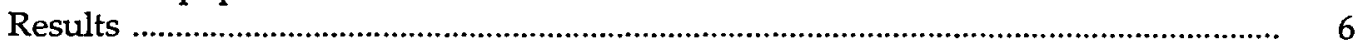

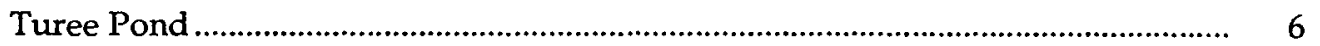

Pleasant Lake ............................................................................................................... 8

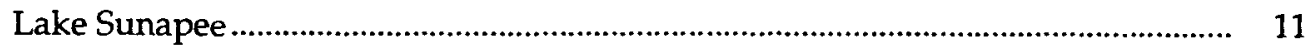

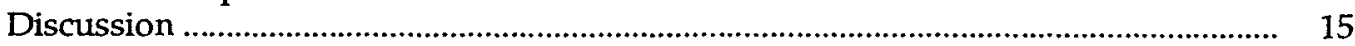

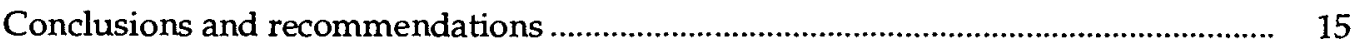

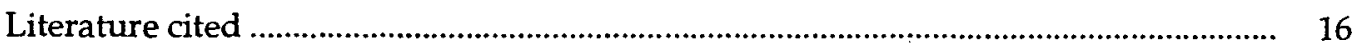

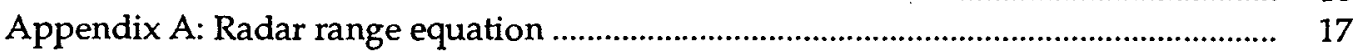

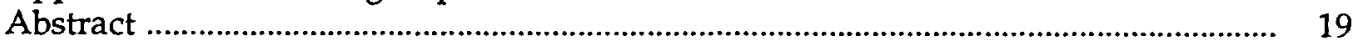

\section{ILLUSTRATIONS}

Figure

1. Acoustic section with a transition from sediments containing gas and no sub-bottom data to a gas-free zone in the center with low signal attenuation and good sub-bottom returns

2. Pulse waveforms selectively amplified within scans from records discussed later

Fiberglass survey boat fitted with $50-\mathrm{MHz}$ antennas attached to vertical brackets for adjusting their position below the water surface

4. Point dipole transmitted radiation directivity patterns in water for the principal antenna planes parallel and perpendicular to the antenna .............. 4

5. Wiggle trace and equivalent line intensity formats for graphic display .............. 5

6. Acoustic radiation directivity, and footprint pattern along a lake floor at a depth of $20 \mathrm{~m}$

7. Location map and approximate survey lines for Turee Pond, Pleasant Lake and Lake Sunapee.

8. Processed data for the $50-$ and $100-\mathrm{MHz}$ profiles from a $200-\mathrm{m}$ line on the northeastern shore of Turee Pond

9. Two-part, unprocessed sub-bottom profile across Pleasant Lake showing variations in material types, layering and the top of bedrock beneath the lake bottom

10. Area B from Figure 9 processed to show more detailed information on the top of bedrock and the returns that suggest sedimentary layering ..........

11. Comparison of profiles from the south end of the Pleasant Lake survey line shown in Figure 9

12. Unprocessed 50-MHz

13. Two processed sections from the Lake Sunapee profile illustrating subbottom detail

14. Acoustic sub-bottom profile obtained at $7 \mathrm{kHz}$ at Lake Sunapee with gain and power set to emphasize the near-bed data. 


\title{
Sub-bottom Surveying in Lakes with Ground-Penetrating Radar
}

\author{
PAUL V. SELLMANN, ALLAN J. DELANEY AND STEVEN A. ARCONE
}

\section{INTRODUCTION}

Information on the properties and distribution of sediments and rock beneath lakes, rivers and shallow backwaters is needed for geologic and engineering investigations. Harbor and channel projects, sedimentation studies and general characterization of sub-bottom materials have relied on acoustic methods because of their ability to penetrate the bottom. However, acoustic equipment can have difficulty in resolving gradational contacts and in penetrating gassy sediments, which can cause high attenuation (e.g., Fig. 1). Previous freshwater investigations using radar (Annan and Davis 1977, Lowe 1985, Haeni et al. 1987, Gorin and Haeni 1989, Beres and Haeni 1991, Kovacs 1991) have revealed sub-bottom information. This report discusses radar equipment that we assembled with consideration given to frequency, power, deployment and analysis of radiation patterns for maximum sub-bottom penetration.

Radar used in conjunction with the acoustic method should allow one to obtain more complete sub-bottom data, since the two approaches have different temporal and spatial sensitivities and respond to different physical properties. At a center frequency of $50 \mathrm{MHz}$ the (typical) radar pulse used in these studies has a duration of about $50 \mathrm{~ns}$, which in water is about $1.7 \mathrm{~m}$ long, about three times the length of the $7-\mathrm{kHz}$ acoustic pulse that we used. The $100-\mathrm{MHz}$ radar pulse that we used was about 1.5 times the length of the acoustic pulse. Therefore, the radar had theoretically less vertical resolution than a standard acoustic bottom sounder, butresolving changes in the subsurface also depends on contrasts in material properties, which cause re-

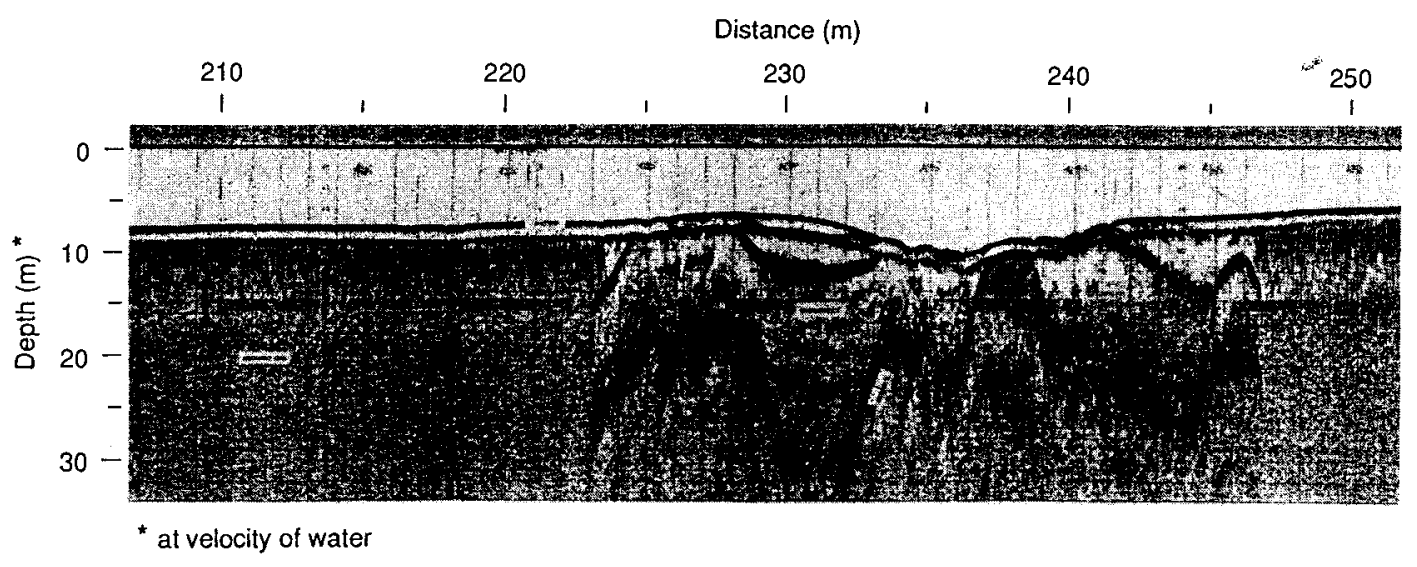

Figure 1. Acoustic section with a transition from sediments containing gas and no sub-bottom data to a gas-free zone in the center with low signal attenuation and good sub-bottom returns (unpublished data courtesy of W.J. Scott 1991). 
flections. Contrasts for radiowave energy are related to variations in dielectric constant and electrical resistivity. These contrasts can differ and in some cases may exceed those at acoustic anomalies, which depend on the product of density and compressional wave velocity. This has been demonstrated by successful use of resistivity methods in investigations of coastal sub-sea permafrost where acoustic anomalies are difficult to detect (Sellmann et al. 1989, Scott and Maxwell 1989).

The primary objective of this research was to determine the performance characteristics of our $50-\mathrm{MHz}$ system as a tool for obtaining sub-bottom data. The results were compared with radar data acquired with a commercially available $100-\mathrm{MHz}$ antenna unit and some preliminary acoustic data obtained at $7 \mathrm{kHz}$. The observations discussed in this report were made at three lake sites in New Hampshire: Both processed and unprocessed data are included. In some cases high quality sub-bottom information was obtained without data processing. However, signal processing substantially improved the records when signal-to-noise ratios were low.

\section{RADAR EQUIPMENT}

\section{General operation}

The commercially available short-pulse radar equipment used for these observations was manufactured by Geophysical Survey Systems (GSSI, North Salem, New Hampshire) and consisted of a control unit, magnetic tape recorder, power supply and a $100-\mathrm{MHz}$ antenna unit containing both transmit and receive antennas. $\mathrm{A} 50-\mathrm{MHz}$ antenna that could be used with the GSSI control unit was constructed for this project and is discussed below. The control unit (SIR Model 4800) generates timing signals to key the transmitter on and off and synchronizes this keying with the receiver. Transmit pulses are triggered at a repetition frequency of approximately $50 \mathrm{kHz}$. The unit also controls the scan rate (how fast individual echo scans are compiled-usually 25 scans/s), the time range over which one wants to view the echoes (tens to thousands of nanoseconds), and the gain to be applied to the echoes. The transmit antenna is excited by a semiconductor device and is designed to radiate a broadband pulse of 1.5 to 3 cycles duration. Consequently, the antenna produces a low gain radiation pattern. A separate, identical receive antenna is employed because echoes can return from nearsurface targets before the transmit antenna has stopped radiating. Electronics for the transmitter and receiver are usually incorporated into the antenna housing. The VHF $(30-300 \mathrm{MHz})$ received signals are converted by sampling into an audio frequency facsimile for filtering, amplification and recording. Data can be simultaneously displayed or quickly played back in strip chart form. Digital recording is available, along with packaged signal processing software that permits several filtering functions and data display formats.

\section{Antennas}

The $50-\mathrm{MHz}$ surveys were made with a pair of compact, easily deployed antennas constructed at CRREL and adapted for sub-bottom surveying. The antennas are linear dipoles, $2.05 \mathrm{~m}$ long, consisting of resistors placed at close intervals for incremental loading. The resistor values used are based on theoretical developments of Wu and King (1964) and a design given by Watts and Wright (1981). However, other experimentation* and our own experience has shown that the precise incremental loading called for by the design is not as critical as the total resistive load. The antennas are unshielded and produced the wavelet shown in Figure 2 with a $3-\mathrm{dB}$ band width of about $25 \%$ of the $50-\mathrm{MHz}$ center frequency, as determined by exact Fourier transformation of a simulated waveform. The physical length of the pulse in water is about $1.7 \mathrm{~m}$. The transmit and receive antennas, along with their electronics, were placed in separate water-tight plastic tubes $17 \mathrm{~cm}$ in diameter and $2.25 \mathrm{~m}$ long. The antennas were spaced $3.7 \mathrm{~m}$ apart by spreaders that positioned an antenna on each side of the boat and also allowed adjustments for antenna depth (Fig. 3). During operation, boat speed was about $4 \mathrm{kn}(2 \mathrm{~m} / \mathrm{s})$ with the antennas 10 to 30 $\mathrm{cm}$ below the surface to maintain consistent coupling. Transmitter output was measured at $980 \mathrm{~W}$ against a 200- $\Omega$ load, but the actual antenna impedance match to the water at any frequency was not determined.

The 100-MHz antenna unit (Model 3107, GSSI, Inc.) radiates a wavelet (Fig. 2) with a frequency spectrum centered at $200 \mathrm{MHz}$ in air and about 100 $\mathrm{MHz}$ when loaded by the proximity of the water. The physical length of the pulse in water is about $0.8 \mathrm{~m}$. The $3-\mathrm{dB}$ bandwidth is about $25 \%$. Both transmit and receive antennas (including electron-

* Personal communication with J.L. Davis, Canpolar Inc., 1990. 


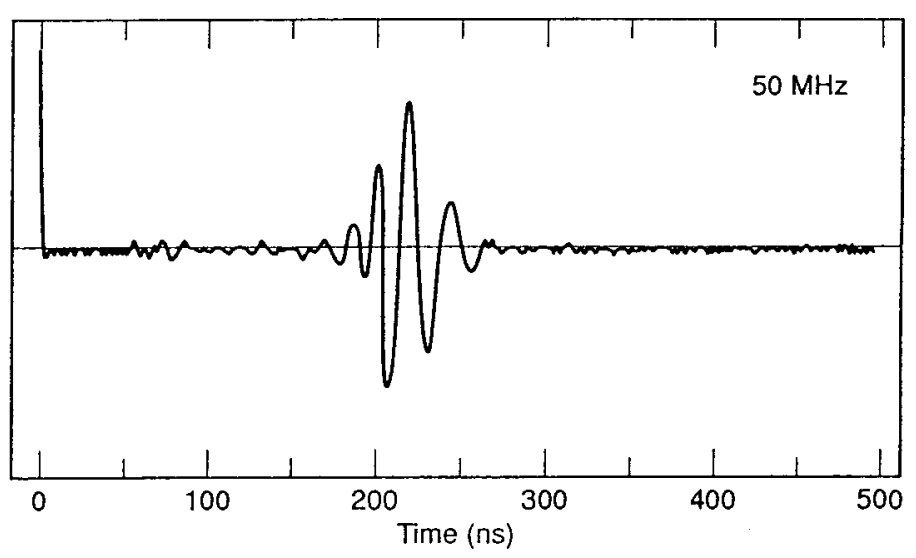

Figure 2. Pulse waveforms selectively amplified within scans from records discussed later. The 2.5 major cycles from the unshielded $50-\mathrm{MHz}$ antenna last about $54 \mathrm{~ns}$ and the 3 cycles from the shielded $100-\mathrm{MHz}$ antenna last about 28 ns.
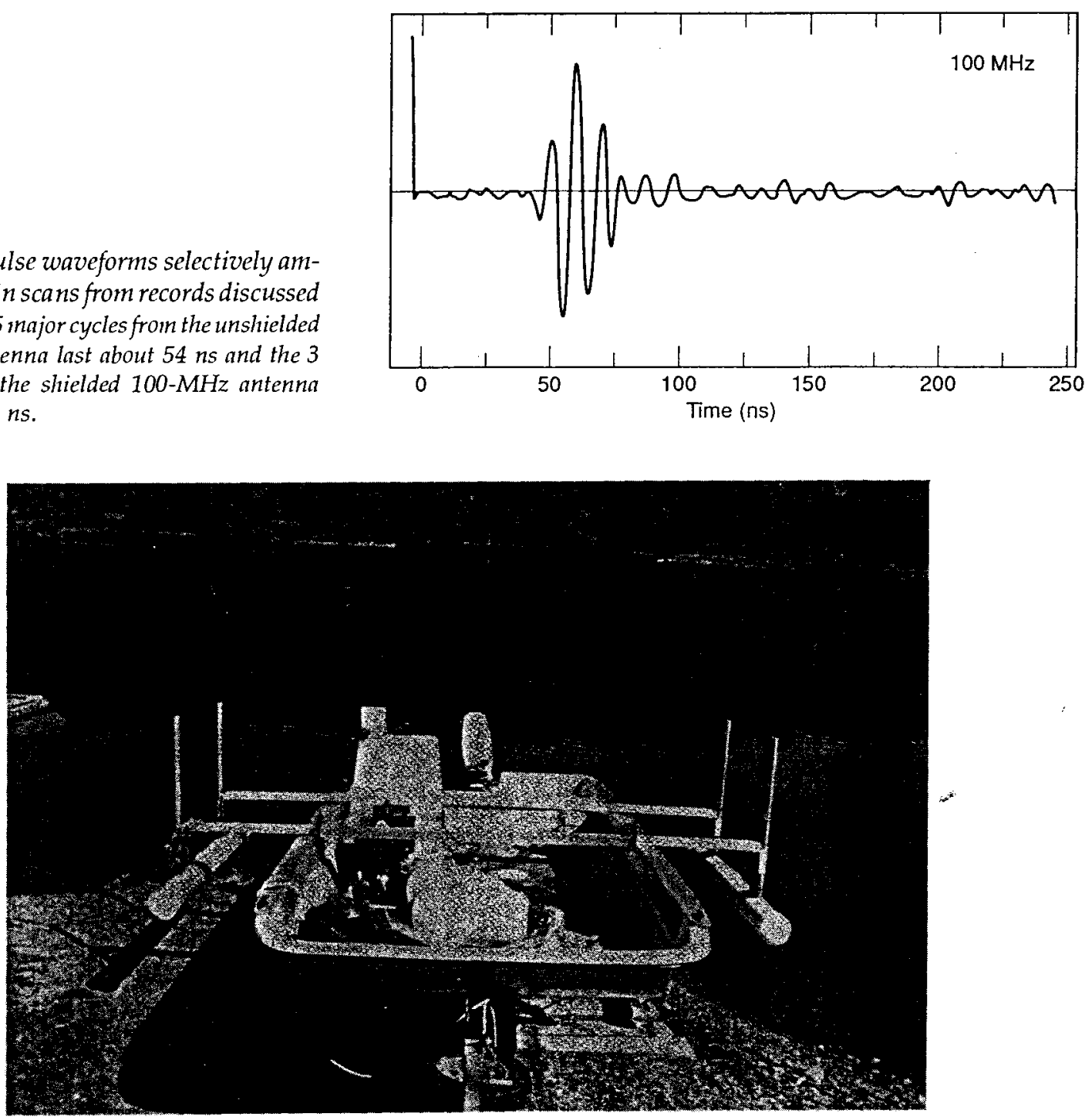

Figure 3. Fiberglass survey boat fitted with 50-MHzantennas (in tubes along gunnels) attached to vertical brackets for adjusting their position below the water surface. The 100$\mathrm{MHz}$ antenna unit was placed inside the boat on the bottom and near the front for best coupling and separation from other equipment. 

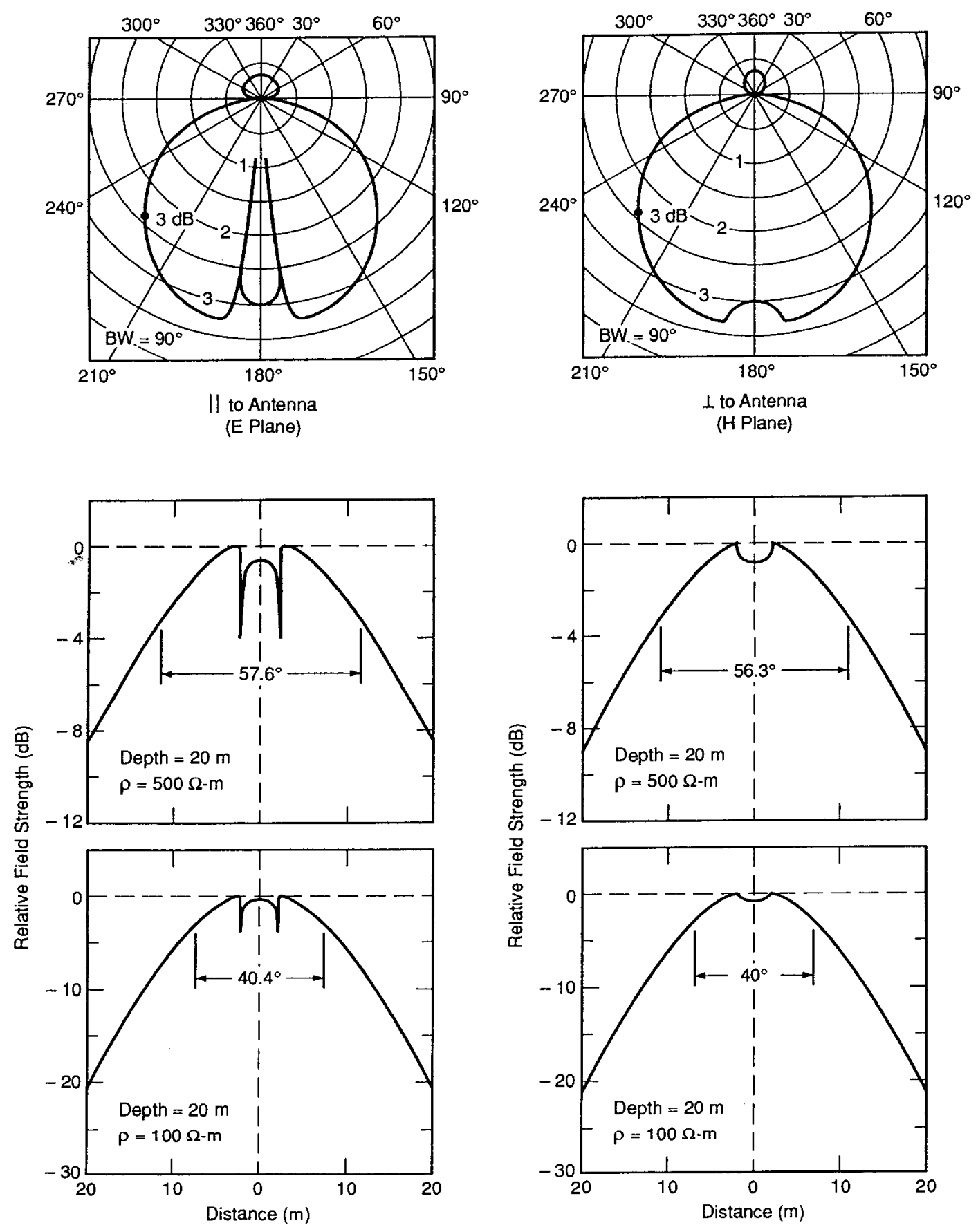

Figure 4. Point dipole transmitted radiation directivity patterns (top two figures) in water for the principal (vertical) antenna planes parallel (E-plane) and perpendicular (H-plane) to the antenna. The bottoin figures show the transmitted signal strength benenth the antenna along the bottom (i.e., the "footprint") at a depth of $20 \mathrm{~m}$ in water of resistivity $\rho$. The loss from geometric beain spreading and absorption narrows the $3-d B$ footprint to $40^{\circ}$.

ics) are housed and separated about $60 \mathrm{~cm}$ in a single backshielded unit. They are flared dipoles with resistive loading to inhibit current oscillation, and are excited by a transmitter that produces about $12-W$ peak radiated power; greater power levels are not possible owing to receiver overload- ing. This antenna was placed on the bottom of the fiberglass boat. The antenna-to-water coupling was not optimal, as evidenced by the large loss shift in center frequency; these antennas are generally designed for good coupling with material of low dielectric constant. 


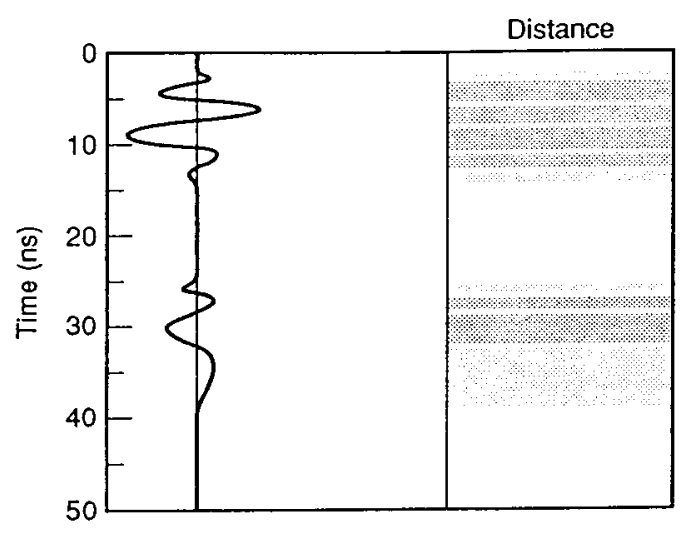

Figure 5. Wiggle trace and equivalent line intensity formats for graphic display.

Subsurface radiation patterns for both antennas are based on the theoretical and experimental results for point dipoles by Annan et al. (1975) and Engheta et al. (1982). This theory shows the 3-dB beamwidth of the radiation intensity from a single point dipole to be confined within an angular width of $90^{\circ}$ in both principal radiation planes: the Eplane and the H-plane (Fig. 4). The E-plane is vertical and parallel to the antenna and the $\mathrm{H}$-plane is also vertical but perpendicular to the antenna. There is also a sharp null in the E-plane pattern in the direction $\psi=2 \sin ^{-1}(1 / n)$, measured from the vertical direction. The quantity $n$ is the real part of the refractive index of water, which, at $23^{\circ} \mathrm{C}$, equals 9 so that $\psi=13^{\circ}$. The theory also shows the radiation levels in air relative to those in water to be suppressed by a factor equal to $n$. This reduction in radiation to the air results in increased radiation to the water (the antenna directivity in the vertical direction is about $7 \mathrm{~dB}$ ), resulting in a slightly directive beam pattern in both principal planes; a dipole in air is directive only in the E-plane. For this reason it was not necessary to shield the $50-\mathrm{MHz}$ antennas from back radiation because of the low radiation level in air.

Figure 4 also shows the projected transmit footprint of a point dipole upon a flat lake bottom at a depth of $20 \mathrm{~m}$, with water having resistivities similar to those found at our study sites. The $3-\mathrm{dB}$ width on the horizontal floor is first narrowed to about $69^{\circ}$ in both planes because of the loss attributable to the greater distance traveled to the sides of the antennas. In addition, attenuation caused by conductive absorption further narrows this transmitted footprint to about $57^{\circ}$ in $500-\Omega$-m water, and to about $40^{\circ}$ in $100-\Omega$-m water (Fig. 4), again because of the greater path length of radiation to the sides of the antennas. The point dipole patterns shown in
Figure 4 are slightly modified when the finite length of the antennas is taken into account. For a linear antenna, the $\mathrm{H}$-plane pattern remains relatively unchanged, but the E-plane pattern becomes more narrow because of the interference effects of different parts of the radiating antenna. Appendix A gives the transmit/receive radar patterns of a vector addition of two 2-m linear arrays of point dipoles, all balanced in strength according to the load resistivity values, with the arrays separated $3.7 \mathrm{~m}$ as was done in the surveys. The patterns show that our $50-\mathrm{MHz}$ antennas produce an effective trans$\mathrm{mit} /$ receive $3-\mathrm{dB}$ footprint at $20 \mathrm{~m}$ depth of only $20^{\circ}$ in the E-plane, comparable to the beamwidth, and about $47^{\circ}$ in the $\mathrm{H}$-plane. This focusing effect is caused by the greater propagation distance to the sides of the antenna and the additional beam directivity factor upon reception. These transmit/receive beamwidth values have been realized experimentally by Rossiter et al. (1991) using a small spherical target in a tank.

\section{Data processing, display \\ and interpretation}

The data were printed directly in the field during the observations using an EPC graphic recorder to evaluate results and monitor equipment performance. This machine displays data in a gray scale line intensity format (Fig. 5) that represents the pulse oscillations as a series of bands. The raw analog data display from the EPC recorder, also used when digital filtering (to remove background noise), removed some desired data. In addition all data were recorded digitally on a GSSI DT6000 tape recorder for later processing and display. The recorder can store up to 65 megabytes of data in scans of 512 or 10248 -bit words on each tape. The digitized data can be read onto a personal computer by a software program (Boucher and Galinovsky 1989) that also processes the data. The program is capable of a variety of filter functions, both horizontal (i.e., over distance, or equivalently, many scans) and vertical (i.e., over time, or equivalently, along one scan). Data can be compressed by stacking of consecutive scans and displayed in either thewiggle trace (amplitude versus time of each scan) or line scan format. All raw data were stacked 6- to 8-fold before digital filtering was applied.Individual scans are easily retrievable with the software.

The graphic capability of the computer printer (HP Paintjet or Tektronix 4693DX) is, in a few cases, of poor quality, so that the weaker reflections seen on the high resolution computer screen may be barely visible after printing. Data interpretation is generally based on the simple echo delay formula 


$$
d=c t / 2 \sqrt{\varepsilon}
$$

where $d=$ depth of a reflector $(\mathrm{cm})$

$t=$ echo time delay (ns)

$c=$ speed of electromagnetic waves in a vacuum $(30 \mathrm{~cm} / \mathrm{ns})$

$\varepsilon=n^{2}$ (relative dielectric constant).

The factor of two in eq 1 accounts for the round trip propagation path of the pulse. Equation 1 applies only to reflections from flat horizontal interfaces at least several wavelengths long, or to scattering from point sources. It can be applied to several layers successively if $\varepsilon$ is known for each layer, and if the time delays to each interface are easily picked off the record.

Signal attenuation with depth is caused by conductive and dielectric absorption, interface transmissions and spherical beam spreading. The beam spreading loss is compensated for by the automatic application of Time Range Gain (TRG), which applies an amplitude gain that increases with time of return or depth. Signal amplitude naturally decreases in inverse proportion to depth and the TRG applied closely matched this loss for depths greater than $8 \mathrm{~m}$ on the deeper surveys.

At any particular depth, the relative echo strengths of lake bed returns are determined by the contrasts in dielectric constant between the water ( $\varepsilon=81$ ) and the sediments. For sediments, $\varepsilon$ is assumed to depend on the relative volumetric ratios of solid and water; denser sediments would have lower water content, a lower value of $\varepsilon$ and produce stronger reflections. Variations in sediment density may also be distinguished along any one scan where reflections become stronger with depth.

\section{ACOUSTIC EQUIPMENT}

A commercial sub-bottom acoustic survey system was used for one of the studies and was manufactured by Ocean Data Systems (Fall River, Massachusetts), which supplied the specification given below. The equipment was designed to obtain accurate bathymetric records and sub-bottom data in water depths of 5 to $120 \mathrm{~m}$. High-frequency (200 $\mathrm{kHz}$ ) and dual low-frequency (Model TCA-3.5/7.0 $\mathrm{kHz}$ ) transducers were mounted approximately 50 $\mathrm{cm}$ below the water surface off the side of the survey boat. The peak power output of the lowfrequency transducer is $2000 \mathrm{~W}$. The system features include automatic initial and bottom-trig- gered time variablegain and a low-ring transducer. The time variable gain is triggered by the $200-\mathrm{kHz}$ bottom return to avoid false triggering by lowfrequency noise. The results are displayed in a line intensity format on a survey fathometer (Model DE-719 RTT) that includes a compact dry paper recorder capable of $30-\mathrm{cm}$ resolution.

In this study sub-bottom acoustic information was obtained with the $7-\mathrm{kHz}$ transducer. The radiational directivity pattern and its equivalent bottom footprint at $20 \mathrm{~m}$ depth are shown in Figure 6. The effective $3-\mathrm{dB}$ transmit footprint width on a flat bottom is only about $32^{\circ}$ and is slightly narrower than those of the point dipole seen in Figure 4 . The effective 3-dB transmit/receive footprint along a flat bottom at $20 \mathrm{~m}$ depth is about $23^{\circ}$ (Appendix A). The pulse width was approximately $0.36 \mathrm{~ms}$ (Fig. 6), which translates to about $54 \mathrm{~cm}$ or about two-thirds the length of the $100-\mathrm{MHz}$ radar pulse and one-third that of the 50 .

\section{RESULTS}

Three lakes located in central and west central New Hampshire were surveyed. The location of these lakes and the approximate location of the profile lines are shown in Figure 7. Turee Pond is near the city of Concord. It ranges up to $3 \mathrm{~m}$ in depth, is about $0.3 \mathrm{~km}^{2}$ in area and was chosen because of its shallow depth and soft organic bed. Pleasant Lake is near the town of New London and was selected for its depth and the occurrence of bedrock at or near the lake bed. Lake Sunapee is a large lake near the town of Newport and was also chosen for its depth and the low conductivity of the lake water. Site selection was aided by preliminary radar surveys.

\section{Turee Pond}

This pond contains low-density organic sediment, has a shallow depth, conductive water and abundant aquatic vegetation in the water columnfeatures that should compromise the performance of both acoustic and radar techniques. Pond margins areoccupied byswampy, bog-like terrain with small trees and bushes established on parts of the bog surface. Shallow parts of the pond support very dense growths of aquatic vegetation and are slowly being filled by peaty organic material. Material at and near the bed seems to consist primarily of dense to very fluid organic material with large clumps of muck often found floating at the surface. A small area with a hard gravelly bottom was 

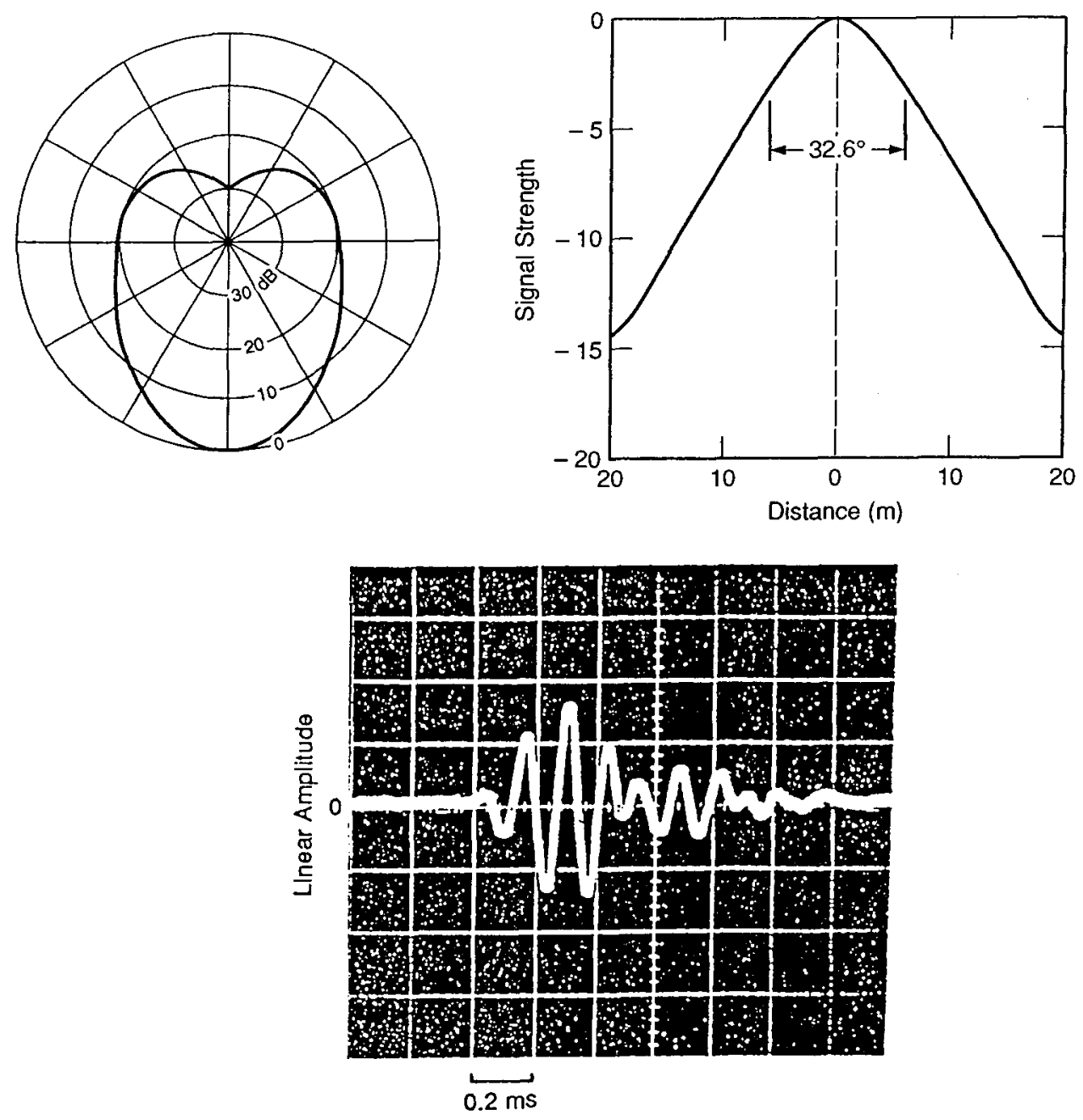

Figure 6. Acoustic radiation directivity (left, top), and footprint pattern along a lake floor at a depth of $20 \mathrm{~m}$ (right, top). The bottom figure is the $7-\mathrm{kHz}$ acoustic pulse shape with a duration of $0.36 \mathrm{~ms}$ for the major 2.5 cycles.

observed near the eastern shore and we assume that this material underlies the organic sediments along our survey line. Accurate water depth was difficult to determine with a sounding pole or line since little resistance was felt in the soft, fluid sediments. In some locations a boat-hook could be pushed more than $50 \mathrm{~cm}$ into the bed with only barely perceptible resistance. The electrical resistivity of the pond water was measured at $100 \Omega-\mathrm{m}$.

Figure 8 shows the results of a survey at two frequencies for a line $200 \mathrm{~m}$ long. The depth scale is linear for the $100-\mathrm{MHz}$ survey because the separation of the transmit and receive antennas is small compared with the water depth. The depth scale for the 50-MHz survey is not linear at these shallow depths because of the 3.7-m antenna spacing. Along the line the brightest returns are from the hard gravelly layer below the bottom. Above these reflections faint returns from the organic bed can be seen at both 50 and $100 \mathrm{MHz}$. All the data were filtered to eliminate low-frequency noise, and the $100-\mathrm{MHz}$ profile was further filtered using a twodimensional Fourier transform to bring out the slanting bottom reflections.

We estimate that at $50 \mathrm{MHz}$ approximately $1 \mathrm{~m}$ of water and $3.5 \mathrm{~m}$ of bed material were penetrated before signal strength from the denser sub-bottom layer was lost in the noise. At $4.5 \mathrm{~m}$ depth, the loss from beam spreading is about $31 \mathrm{~dB}$ and that from reflection from the bottom of the saturated layer is estimated at $14 \mathrm{~dB}$. This totals $45 \mathrm{~dB}$ and leaves about $51 \mathrm{~dB}$ for losses in the water and organic layer 

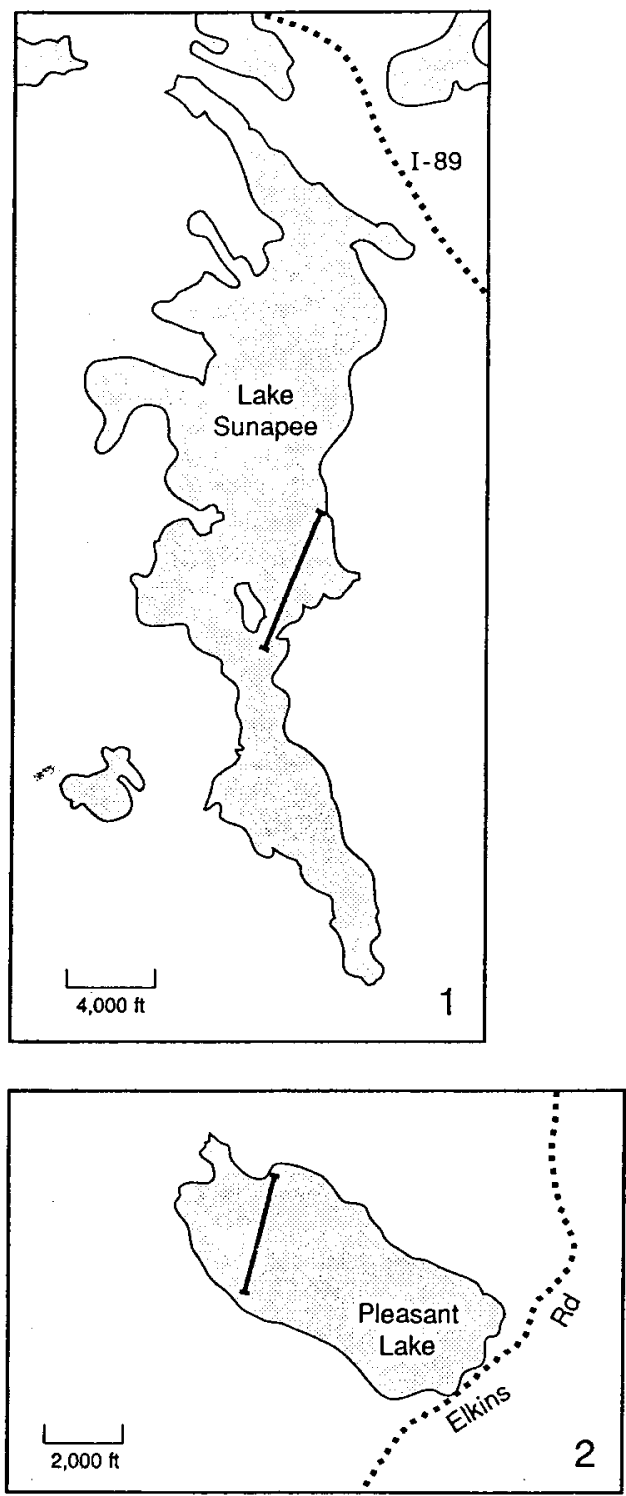
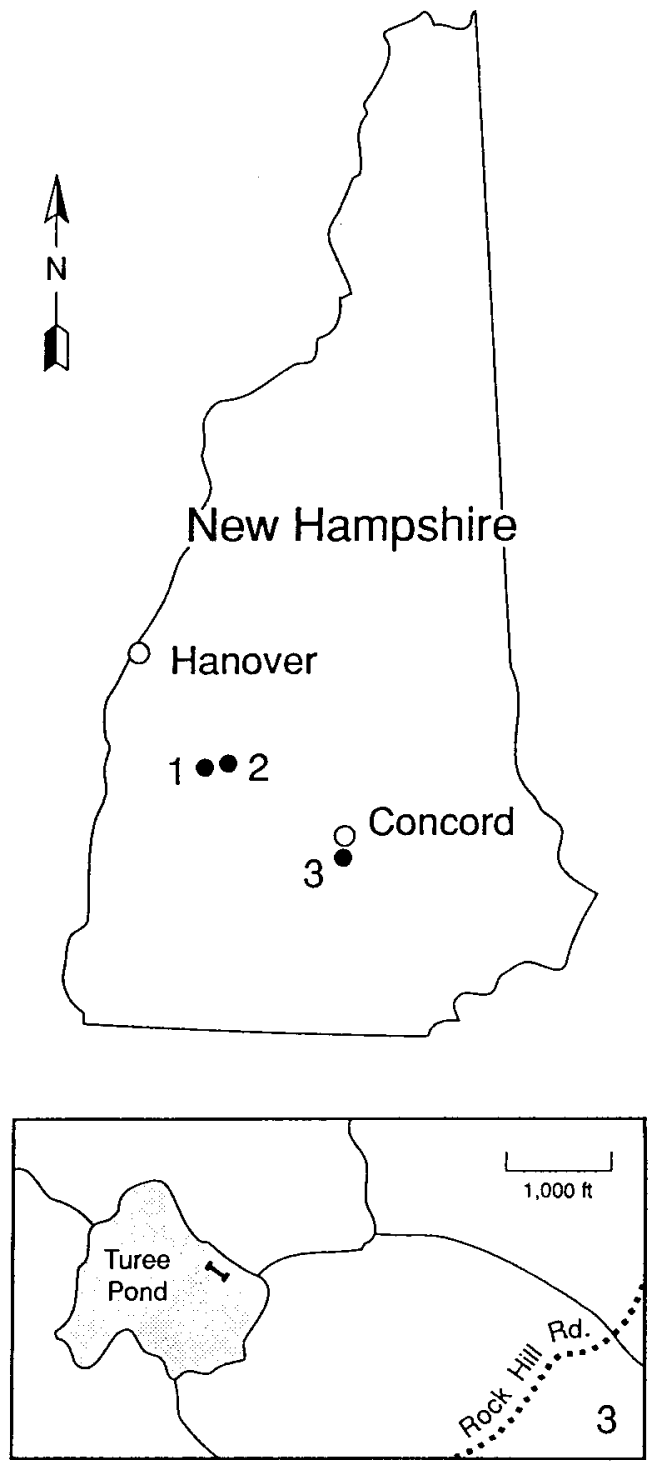

Figure 7. Location map and approximate survey lines for Turee Pond, Pleasant Lake and Lake Sunapee $(1 \mathrm{ft}=0.3048 \mathrm{~m})$.

(the transmission coefficient of the water/organic interface is nearly 1) since limited radar performance can be expected when total round-trip propagation loss reaches about $96 \mathrm{~dB}$ (see Discussion). The water resistivity of $100 \Omega-m$ gives an attenuation rate of about $2 \mathrm{~dB} / \mathrm{m}$ and a $4-\mathrm{dB}$ loss. Therefore, the attenuation rate attributable to conductive absorption (see Appendix A) in the organic muck appears to be nearly $7 \mathrm{~dB} / \mathrm{m}$, which corresponds to a reasonable resistivity of about $25 \Omega-\mathrm{m}$.

\section{Pleasant Lake}

This lake reaches depths of approximately $30 \mathrm{~m}$, is of high resistivity $(400 \Omega-\mathrm{m} ; 0.5 \mathrm{~dB} / \mathrm{m}$ attenuation rate), and has bedrock at or near the lake bed. The high-resistivity water permitted good penetration and allowed a radar performance figure to be estimated (see Discussion). Preliminary surveys showed intense bottom reflections, indicating that strong contrasts existed between the dielectric constants of the bedrock, water and the water-satu- 


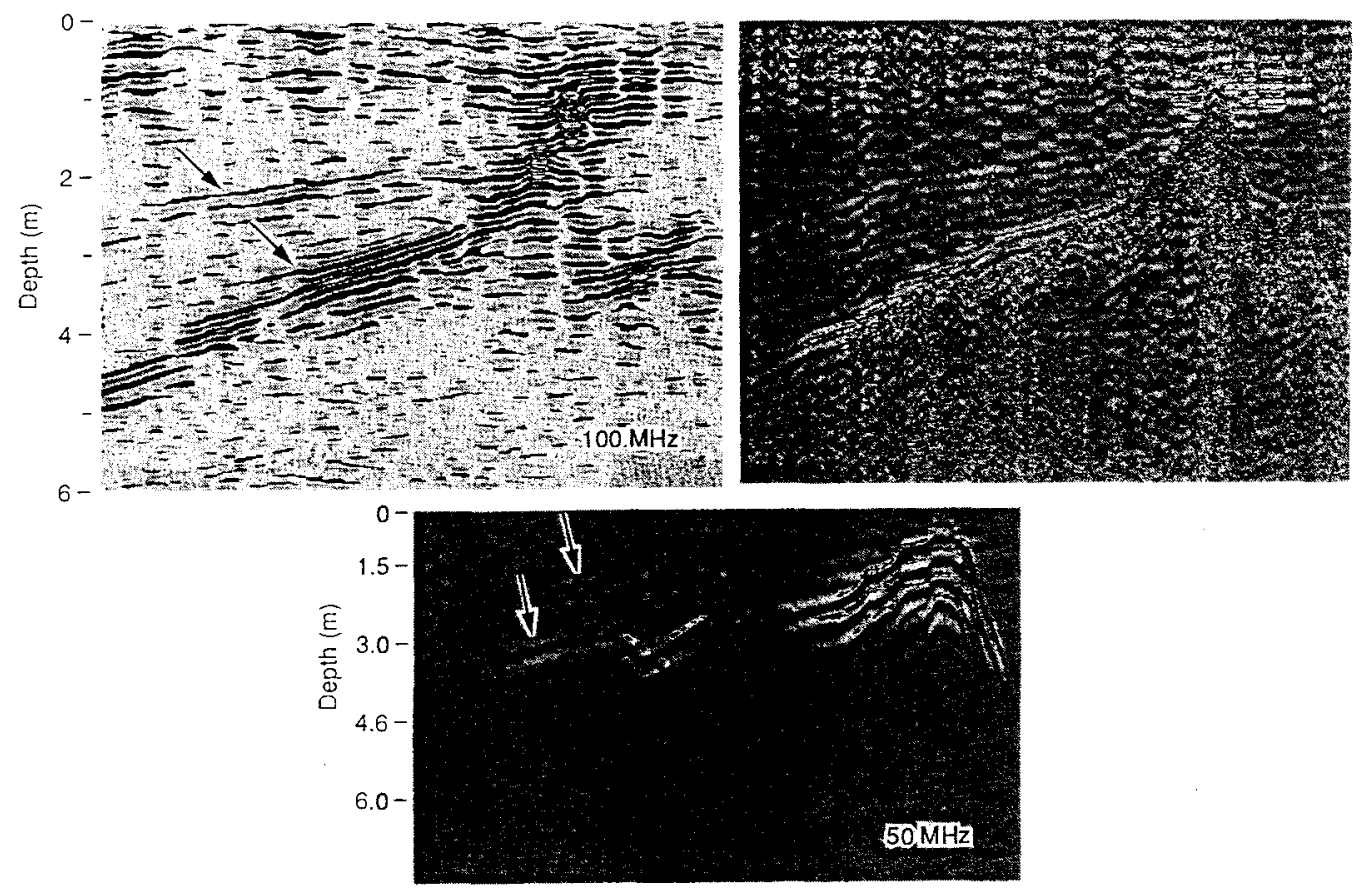

Figure 8. Processed data for the 50- and 100-MHz profiles from a 200-m line on the northeastern shore of Turee Pond. The arrows indicate the water/organic and organic/mineral interfaces. All profiles have been filtered to eliminate low-frequency noise. The 100-MHz profile on the left has been further processed using a two-dimensional Fourier transform filter to bring out the slanting bottom reflections. The depth scales are calibrated for water.

rated sediments. The bed rock was mapped as quartz monzonite by Billings (1956), which, in our frequency range, has a dielectric constant of about 6 (Campbell and Ulrichs 1969).

Figure 9 is an unprocessed 50-MHz survey, 0.8 $\mathrm{km}$ long, near the west end of the lake made at a time range of $1800 \mathrm{~ns}$. It begins near the north side of the lake and extends to the south shore, passing a maximum depth of $21.5 \mathrm{~m}$. The depth scale, which is slightly nonlinear to about $20 \mathrm{~m}$ because of the $3.7-\mathrm{m}$ separation of the antennas, is based on the value $\varepsilon=81$ for water. The constant horizontal bands across the record are the result of antenna ringing because of impedance mismatches between the antenna and the water, and internal system noise. These bands are easily removed by "background removal" filtering (shown later), but were not removed from this figure because the (horizontal) filtering also tends to remove horizontal reflections from flat portions of the lake bed.

This profile shows obvious features at and below the bed, including bedrock outcrops, the bedrock surface below the bed, contrasts in sediment type and sedimentary patterns with strong indica- tions of layering. In most cases it appears that the bed surface, bedrock outcrops and the materials within the sedimentary bed produce strong reflections. However, the change or absence of signal strength from within the bed indicates changes in material properties, most likely related to density. For example, at the southern end around location $A$ and at the northern end around location B, it appears that the irregular bedrock surface can be traced beneath the bed sediments. However, contrasts in reflection strength (not apparent in this black and white reproduction) at A suggest two distinct types of sediment (low density over high density), whereas at $B$ the sediments appear thicker and seem to contain more apparent layering. Detailed local information on sedimentation can also be seen in the center of the profile at location $C$, where sediments are deposited in a small basin between rock knobs that extend above the bed.

The $B$ area in Figure 9 is shown in more detail in Figure 10. This section has been processed to remove the horizontal bands of background noise and also variations in overall gain between scans. The section shows the irregular and fairly continu- 

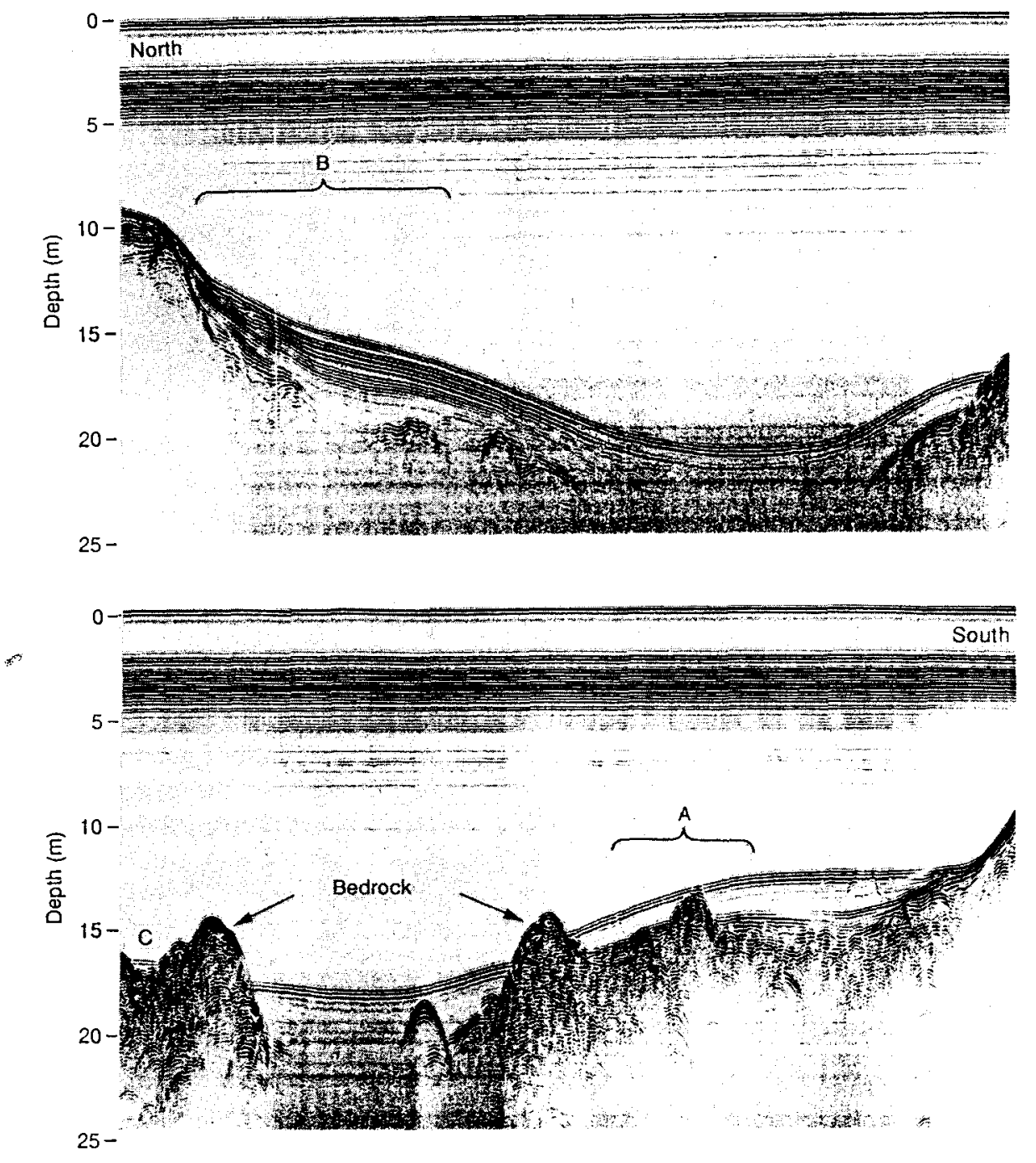

Figure 9. Two-part, unprocessed sub-bottom profile, approximately $1 \mathrm{~km}$ long, across Pleasant Lake showing variations in material types, layering and the top of bedrock beneath the lake bottom. The vertical exaggeration is about 20:1.

ous nature of the top of the bedrock and the apparent configuration of the sediments blanketing its surface. Changes in the shape and spacing of the reflection bands from the sediment indicate at least four layers above the bedrock. It appears that sediments accumulated behind and between the bedrock knobs. Once the rock was covered, the apparent bedding became more regular in response to the more subdued local relief.

The minimum depth of penetration into the bed sediments can be estimated by assuming that the sediments above the bedrock in area $B$ have the velocity of water $(\varepsilon=81)$. With this assumption, the depth scale applies to sediment thickness and shows a minimum penetration also of $6 \mathrm{~m}$. A maximum penetration depth at this location could have been about $9 \mathrm{~m}$ if the sediments were at saturation. In addition, beneath the bottom reflection there are numerous diffraction hyperbolas seen throughout the record. The deeper of these events occur at time delays too great to be interpreted as objects to the side of the survey line because the transmit/receive radiation pattern is too narrow (see Disculssion). The deep hyperbola seen at the south end of area $A$ in Figure 9 is at a minimum depth of $6 \mathrm{~m}$. Hyperbolas seen in the next study are far deeper. 


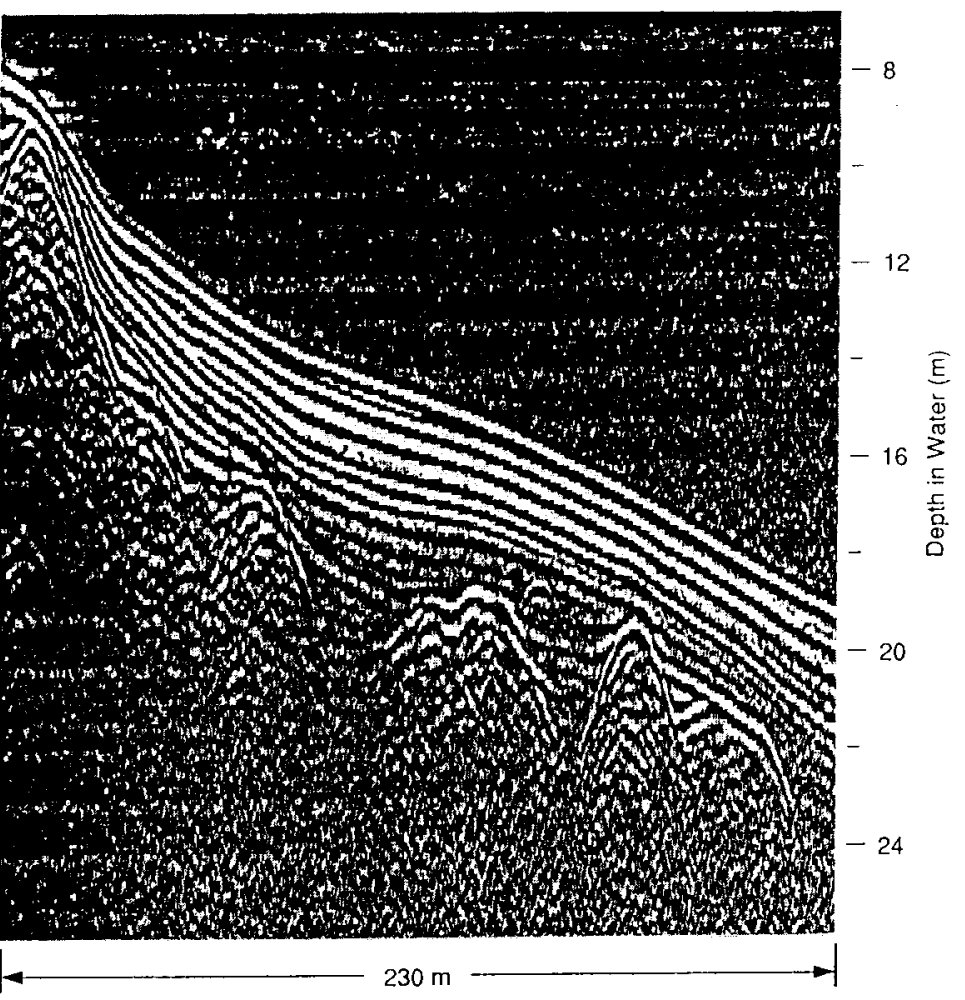

Figure 10. Area B from Figure 9 processed to show more detailed information on the top of bedrock and the returns that suggest sedimentary layering. The irregular reflections at depth (apparent top of bedrock) are less difficult to recognize after noise was suppressed.

Figures $11 \mathrm{a}$ and $\mathrm{b}$ compare $50-$ and $100-\mathrm{MHz}$ profiles at the northern end of the Pleasant Lake line out to a water depth of $16 \mathrm{~m}$ where the 100 $\mathrm{MHz}$ returns are no longer visible. We made this comparison to determine the improvement in resolution of apparent sedimentary layering using the shorter $100-\mathrm{MHz}$ pulse. Generally, layers whose thickness corresponds to about half the pulse width can be resolved. This may be the case at location $\mathrm{C}$, where there are twice as many bands for a given distance below the bed at $100 \mathrm{MHz}$ as there are at 50 $\mathrm{MHz}$. (Each pulse band does not represent an individual layer since about 5 to 6 bands-positive and negative cycles-usually represent one pulse.) Thus, there is less overlap between reflections at $100 \mathrm{MHz}$ and better resolution. Detailed layering is suggested because the bands merge and spread, have a logical configuration in relation to the rock, and are of fairly even intensity. These patterns suggest significant contrasts in dielectric properties between layered sediments.

\section{Lake Sunapee}

Figures 12 and 13 show sub-bottom profiles from the Sunapee line located in Figure 7 . The maximum water depth along the survey line was $20 \mathrm{~m}$ and several surface water samples gave a resistivity value of $500 \Omega-\mathrm{m}$, a value that gives only $0.45 \mathrm{~dB} / \mathrm{m}$ (one way) propagation attenuation at 50 $\mathrm{MHz}$. The bed is fairly flat, but interrupted by prominences at $0.4 \mathrm{~km}$ (reported by divers to be boulders) and $1.3 \mathrm{~km}$ (assumed to be bedrock).

The strongest returns along the line are associated with the bedrock features and areas that appear to consist of denser sediments; it appears that there are at least two different sediment types along the line. Denser sediments with a stronger return appear at the bed along the southern part of the line (e.g., at $0.1-0.3 \mathrm{~km}$ and at $0.6-0.7 \mathrm{~km}$ ). Weaker returns, indicative of sediment of lower density, are evident in both processed and unprocessed data and occur in the depressions at 0.0, 0.55 and $0.75 \mathrm{~km}$. Speaking quantitatively, given a nor- 

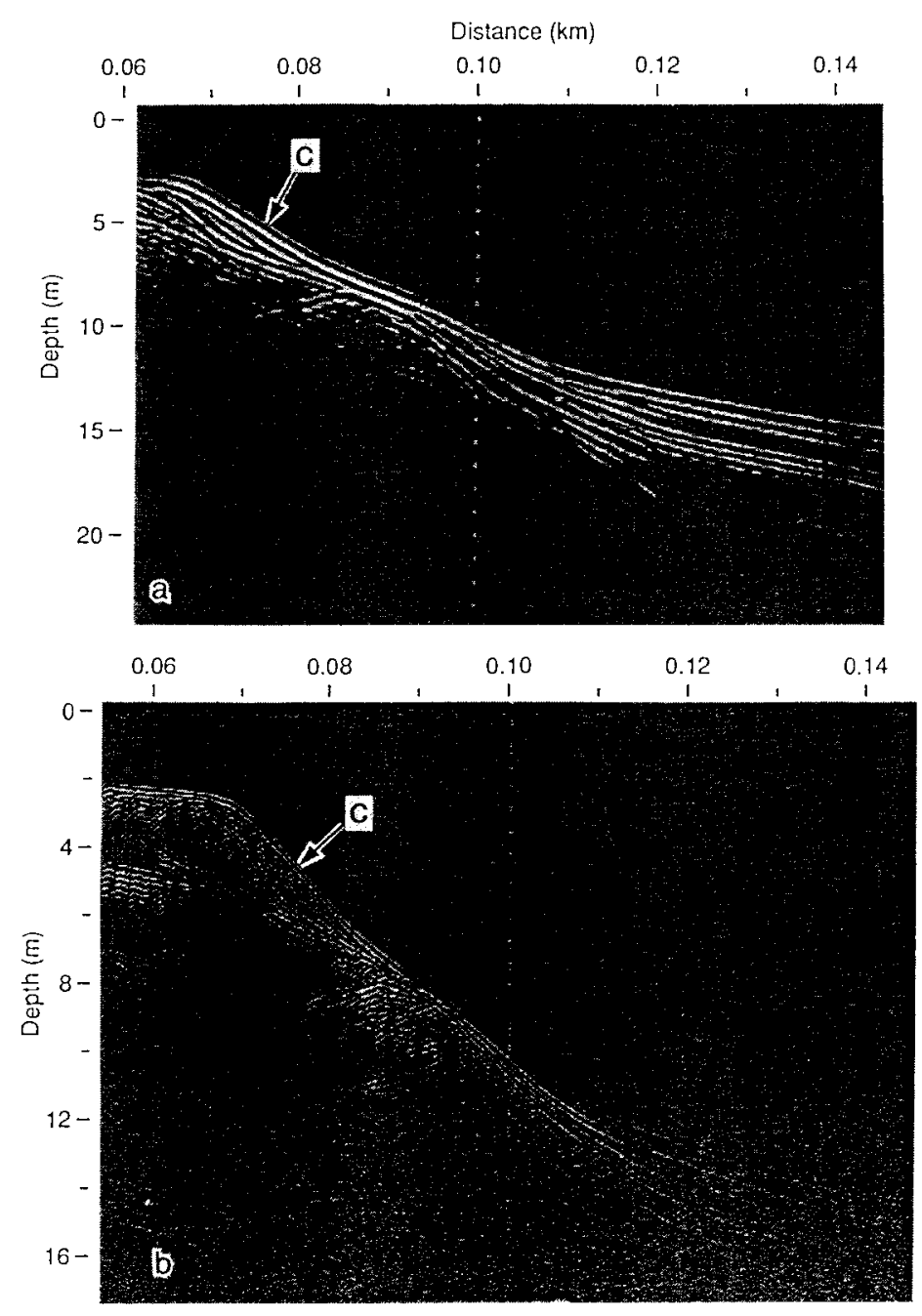

Figure 11. Comparison of a) $50-\mathrm{MHz}$ profile, and b) $100-\mathrm{MHz}$ profile from the south end of the Pleasant Lake surveyline shown in Figure 9.

malized peak-to-peak signal strength amplitude of 1.0 for the denser sediments at $0.1-0.3 \mathrm{~km}$, we see that the relative amplitudes at $0.0,0.55$ and $0.75 \mathrm{~km}$ are 0.33 (adjusted for extra conductive absorption because of greater strength), 0.83 and 0.30 respectively. Amplitude changes attributable to variations in depth alone were compensated for by the TRG, which closely matched theoretical changes from spherical beam spreading. The denser material may be a till-like deposit containing some rocks and boulders, as suggested by the scattered hyperbolas at $0.1-0.2$ and $0.6-0.7 \mathrm{~km}$. The lowdensity material contains apparent bedding and minor indication of small local reflectors. Processed records show this material filling a depression in the denser sediment (Fig. 13a) and stacked up against the south side of the bedrock ridge near the center of the profile (Fig. 13b). It also can be seen completely covering the bed to the north of this ridge (Fig. 12 or 13b). We believe that the rapid increase in signal strength on the north end indicates a hard sandy bottom. The low-density sediments with weak indications of bedding at the north end of Figure 12 appear to overlie more dense sediment that also has little apparent bedding.

As was seen in the Pleasant Lake data, there are numerous diffraction hyperbolas that appear below the bottom. The boulder pile at $0.4 \mathrm{~km}$ in Figure 12 is the source of many of the diffractions in this vicinity. However, there are some very deep dif- 


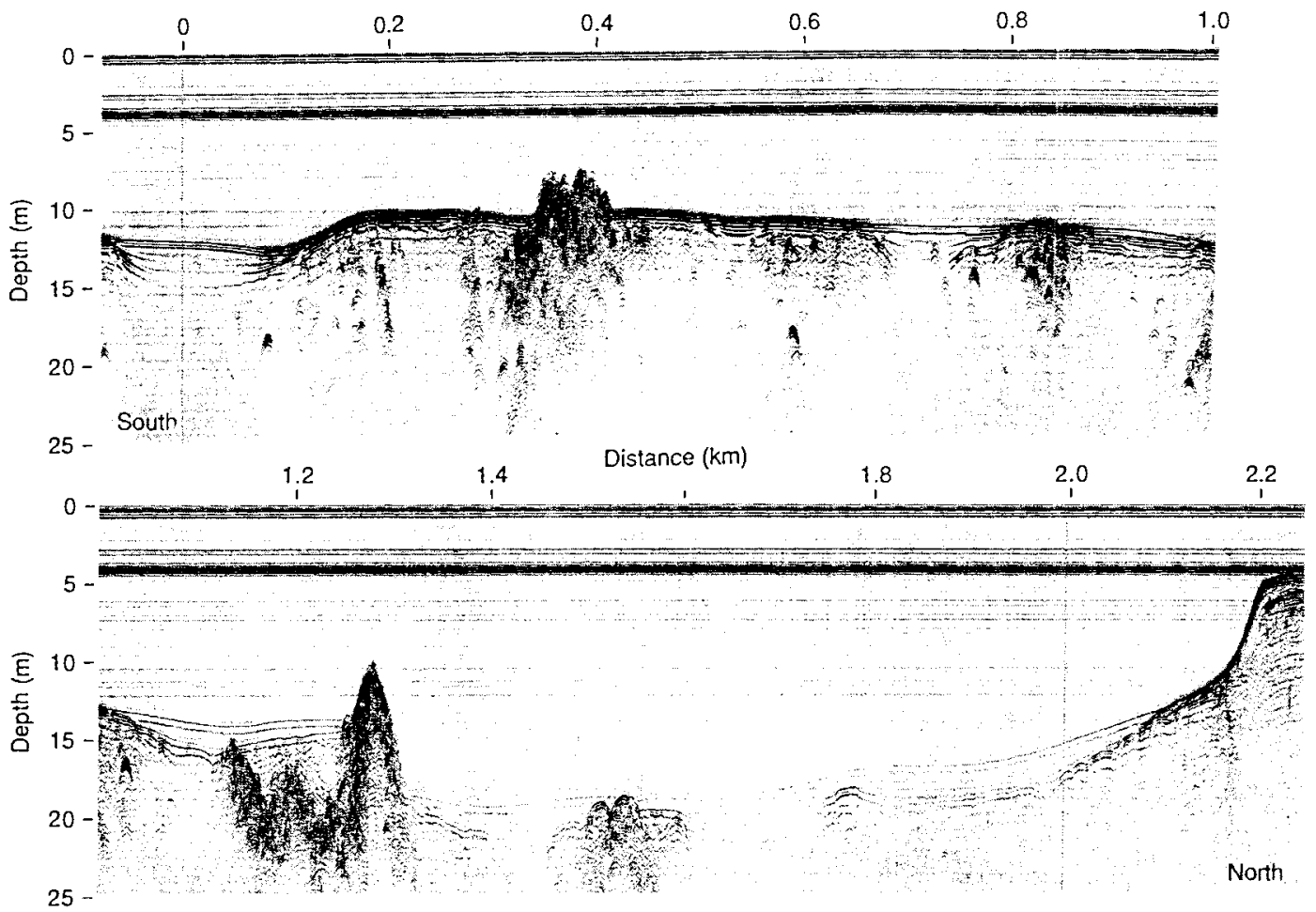

Figure 12. Unprocessed 50-MHz sub-bottom profile, $2.2 \mathrm{~km}$ long, from Lake Sunapee.

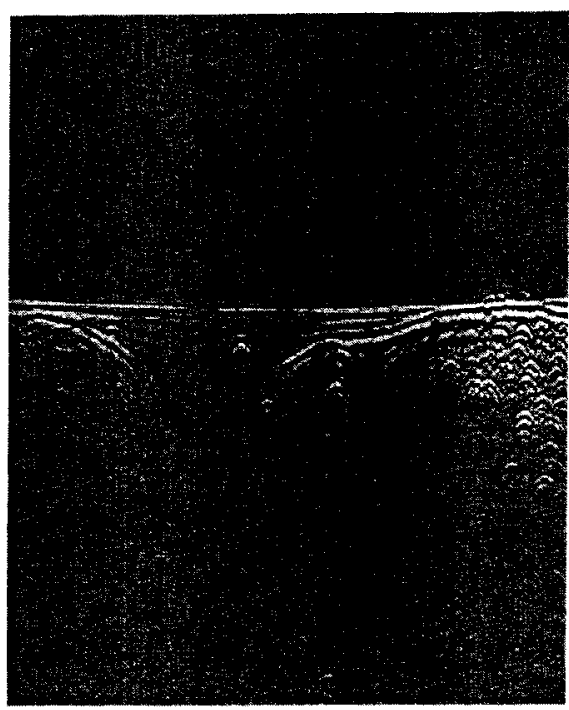

a. Low-density material filling a depression in sediment of greater density located at $0.75 \mathrm{~km}$ in Figure 12.

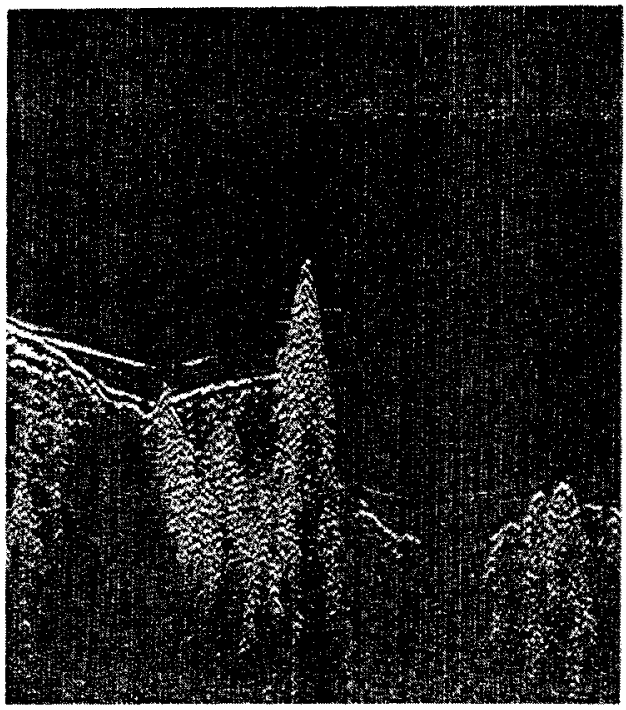

b. Layered sediments deposited behind the bedrock ridge at $1.3 \mathrm{~km}$ in the Lake Sunapee profile. The stronger returns from sediments deposited between the bedrock irregularities adjacent to the ridge suggest they have greater density than the overlying inaterial.

Figure 13. Two processed sections from the Lake Sunapee profile illustrating sub-bottom detail. 

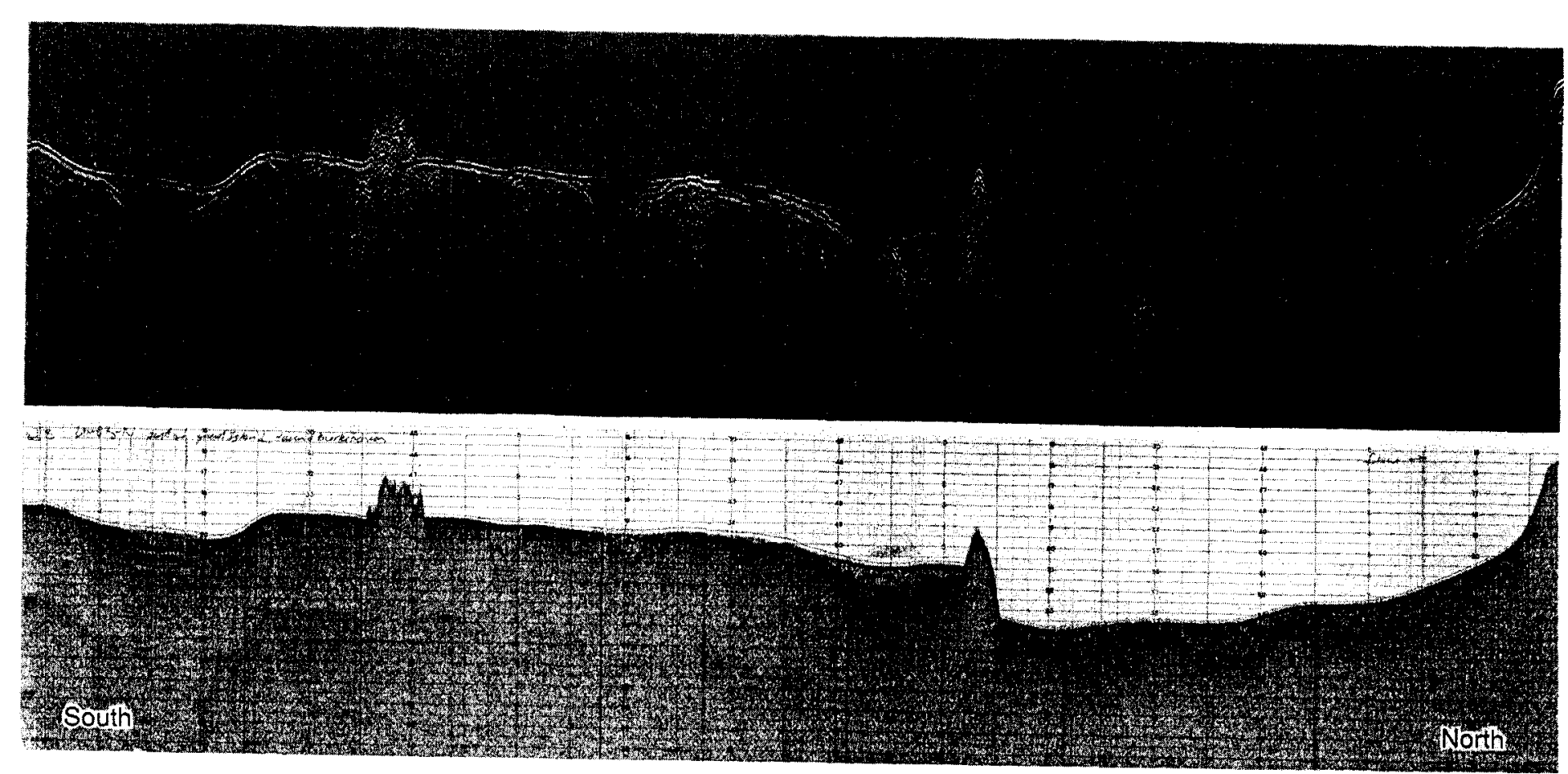

Figure 14. Acoustic sub-bottom profile (bottom) obtained at $7 \mathrm{kHz}$ at Lake Sunapee with gain and power set to emphasize the near-bed data. Low-density sediments are a lighter tone. The 2.2-km-long processed radar profile above from data shown in Figure 12 is provided for
comparison. 
fractions between 0.30 and $0.35 \mathrm{~km}$ that we believe may be sub-bottom, for reasons given in the Discussion.

Figure 14 allows comparison of the $50-\mathrm{MHz}$ radar data from Figure 12 with a $7-\mathrm{kHz}$ acoustic profile along the same line. The $7-\mathrm{kHz}$ system was set for the greatest sensitivity to returns from the near-surface sediments, and the profile delineates the upper and lower limits of the low-density deposits much the same as shown in the radar data. However, the acoustic profile fails to show all the detailed contrasts between types of bed material and any of the hyperbolic returns evident in the radar results. Since the acoustic pulse is about onethird the length of the radar pulse, the superior radar resolution could be ascribable to greater contrasts within the electromagnetic properties as compared to contrasts within the acoustic properties. For example, indications of layering in the depressions at 0.2 and $0.95 \mathrm{~km}$ can be seen in the radar record, but not in the acoustic data. The separation of these radar returns ranges from 50 to $80 \mathrm{ns,}$ which, for any dielectric constant corresponding to a (30-70\%) range in sediment water volume, allows the layers to range from 1 to $3 \mathrm{~m}$ in thickness, a range that should be within the resolution capabilities of the acoustic system.

\section{DISCUSSION}

There are several factors that influence the performance of a radar, performance being defined as the ratio in decibels of the weakest detectable signal to the transmitted signal (see Appendix A). System losses (e.g., mismatch at the water interface and internal cable reflections) are difficult to estimate. However, losses from beam spreading, conductive absorption and target reflectivity can be calculated to estimate propagation loss and, therefore, the penetration achieved in a freshwater survey. To make this calculation, we chose the greatest depth crossed by any survey line ( $29 \mathrm{~m}$, Pleasant Lake) where a bottom return was visible in the data. By use of eq $A 3$, at this depth the geometric beam spreading gives $46 \mathrm{~dB}$ of loss, conductive and relaxation absorption accounts for $31 \mathrm{~dB}(400-\Omega-\mathrm{m}$ water), and the bottom reflectivity gives $14 \mathrm{~dB}$ of loss (assuming a water-saturated mineral sediment having an $\varepsilon=36$ ). This adds up to at least $91 \mathrm{~dB}$ of propagation loss for a round-trip return from the bottom. A hyperbolic reflection observed beneath the bottom return is evidence of a low-reflectivity bottom and additional power available. Therefore, these loss calculations imply that with a highreflectivity hard bedrock $(\varepsilon=6)$ bottom and water of similarly low conductivity, bottom returns well above noise could be obtained in water over $38 \mathrm{~m}$ deep. In $100-\Omega-m$ water this depth decreases to only about $12 \mathrm{~m}$.

In both the Pleasant Lake and Lake Sunapee data, there are sections with numerous hyperbolas, many of which appear to emanate from beneath the bottom. The fact that some appear so deep (e.g., over twice the water depth) suggests that they may actually be on the bottom, but far to the side of the line. However, the amplitudes of these events are not consistent with radar range and attenuation calculations (see Fig. A1a). For example, the diffraction event at $21 \mathrm{~m}$ depth at $0.32 \mathrm{~km}$ in Figure 12 is only $10 \mathrm{~dB}$ weaker than the bottom reflection at $9 \mathrm{~m}$ depth. If this event was from the side of the antenna, the angle from vertical would be $65^{\circ}$, at which there is about $37 \mathrm{~dB}$ of loss in the radar footprint pattern at $21 \mathrm{~m}$ distance. Since the TRG compensates for only the spherical spreading loss (about $15 \mathrm{~dB}$ from 9 to $21 \mathrm{~m}$ ) to within $2 \mathrm{~dB}$ at this depth, the amplitude observed is just too strong to have the event come from off-center. Another possible explanation is that these events are within the sub-bottom, but are less deep than they appear because of unusually high dielectric constants in the saturated sediments.

The radar data and results of the preliminary acoustic survey seen in Figure 14 provide an interesting comparison. The techniques confirm the configuration of the low-density deposits near the bed. However, at these depths greater sub-bottom detail is revealed in the radar profile. This increase in detail is most likely caused by greater electrical impedance contrasts at the sedimentary boundaries; it cannot be attributed to a lack of clutter in the radar data as the acoustic system has a more narrow effective beamwidth and a shorter pulse length.

\section{CONCLUSIONS AND RECOMMENDATIONS}

Unprocessed radar data provided detailed information on apparent sedimentary bedding and layering, sediment properties and distribution, and variations in depth to bedrock beneath the bed. In shallow lake water of low resistivity $(100 \Omega-\mathrm{m})$, low-density organic sediments, 1 to $4 \mathrm{~m}$ thick, were profiled over denser bed material. In lake water of higher resistivity (400-500 $\Omega-\mathrm{m})$, bed penetration 
to at least $6 \mathrm{~m}$ was obtained in water over $15 \mathrm{~m}$ deep. Data processing provided significant improvements to the records, particularly where coherent noise levels were high. The radar and acoustic techniques supported each other in confirmation of gross sub-bottom features, while the radar seemed to provide more detail for features near the bed. The $50-\mathrm{MHz}$ system appears capable of detecting signals that have suffered over $100 \mathrm{~dB}$ of propagation loss.

The results presented are mainly qualitative, as we could not directly verify all sub-bottom conditions at the three lakes investigated. Sub-bottom conditions (i.e., the depth of the organic layer) at Turee Pond are accessible and will be investigated more thoroughly. A study of low-density organicmineral sediments is needed to estimate thickness. This can be done either by calibration of the radar record at setected points where the thickness can be directly measured, or by inserting waterproofed antennas into the muck at a fixed separation and measuring the time delay of the propagating pulse.

\section{LITERATURE CITED}

Annan, A. P., W. M. Waller, D. W. Strangway, J. R. Rossiter, J. D. Redman, and R. D. Watts (1975) The electromagnetic response of a low-loss, 2-layer, dielectric earth for horizontal electric dipole excitation. Geophysics, 40(2): 285-298.

Annan, A.P. and J.L. Davis (1977) Impulse radar applied to ice thickness measurements and freshwater bathymetry. Geological Survey of Canada, Paper 77-1B, p. 63-65.

Beres, M., Jr. and F.P. Haeni (1991) Application of ground-penetrating-radar methods in hydrological studies. Ground Water, 29(3): 375-386.

Billings, M. P. (1956) The Geology of New Hampshire. Concord, New Hampshire: Department of Resources and Economic Development.

Boucher, R. and L. Galinovsky (1989) RADAN 3.0, signal processing software for the GSSI System. North Salem, New Hampshire: Geophysical Survey Systems, Inc.

Campbell, M. J. and J. Ulrichs (1969) Electrical properties of rocks and their significance for lunar radar observations. Journal of Geophysical Research, 74(25): 5867-5881.
Engheta, N., C. H. Pappas, and C. Elachi (1982) Radiation patterns of interfacial dipole antennas. Radio Science, 17: 1557-1566.

Gorin, S.R. and F.P. Haeni (1989) Use of surfacegeological methods to assess riverbed scour at bridge piers. U.S. Geological Survey Water Resources Investigations Report 88-4212.

Haeni, F.P., D.K. McKeegan and D.R. Capron (1987) Ground-penetrating radar study of the thickness and extent of sediments beneath Silver Lake, Berlin and Meriden, Connecticut. U.S. Geological Survey Water Resources Investigations Report 854108.

Kovacs, A. (1991) Impulse radar bathymetric profiling in weed-infested fresh water. USA Cold Regions Research and Engineering Laboratory, CRREL Report 91-10.

Lowe, D.J. (1985) Application of impulse radar to continuous profiling of tephra-bearing lake sediments and peats: an initial evaluation. New Zealand Journal of Geology and Geophysics, 28: 667-674. Rossiter, J. R., E. M. Reimer, L. A. Lalumiere and D. R, Inkster (1991) Radar cross section of fish. In Proceedings of Workshop on Ground Penetrating Radar, Ottawa, Canada, May 24-26, 1988 (J. A. Pilon, Ed.); also as Geological Survey of Canada paper $90-$ 4, 1990.

Scott, W. J. and F. K. Maxwell (1989) Marine resistivity survey for granular materials, Beaufort Sea. Canadian Journal of Exploration Geophysics, 25(2).

Sellmann, P. V., A. J. Delaney and S. A. Arcone (1989) Coastal subsea permafrost and bedrock observations using dc resistivity. USA Cold Regions Research and Engineering Laboratory, CRREL Report 89-13.

Siggins, A. F. (1990) Experience with ground penetrating radar in geotechnical applications. In Third International Conference on Ground Penetrating Radar, Lakewood, Colorado, May 14-18, 1990, abstracts of the technical meeting (J. E. Lucius, G. R. Olhoeft and S. K. Duke, Eds.). USGS, Open-file Report 90-414, p. 62. Watts, R. D. and D. L. Wright (1981) Systems for measuring thickness of temperate and polar ice from the ground or from the air. Journal of Glaciology, 27(97): 459-469.

Wu, T. T., and R. W.P. King (1964) The cylindrical antenna with nonreflecting resistance loading. IEEE Transactions of Antennas Propagation, AP-12(3):369373. 


\section{APPENDIX A: RADAR RANGE EQUATION}

The ratio of power received $P_{r}$ from a finite reflector of cross section $\sigma$, to power $P_{t}$ radiated by the transmitting antenna is

$$
P_{\mathrm{r}} / P_{\mathrm{t}}=L G^{2} \lambda^{2} \sigma \mathrm{e}^{-4 \beta R} /\left(64 \pi^{3} R^{4}\right)=(\mathrm{L})(\sigma)\left(G^{2} \lambda^{2} / 4 \pi\right)\left(\mathrm{e}^{-4 \beta R}\right)\left(1 / 16 \pi^{2} R^{4}\right)
$$

where $L=$ system losses (e.g., mismatches between cables and antennas or at the antenna/ ground interface)

$G=$ antenna gain

$\lambda=$ transmitted wavelength

$R=$ range to the target interface

$\beta=$ attenuation function of the propagation medium.

The third term in parentheses accounts for the antenna properties and evaluates to about $-0.5 \mathrm{~dB}$ for the $50-\mathrm{MHz}$ antenna in water. The fourth term accounts for conductive absorption. The fifth term accounts for losses due to $1 / R^{2}$ spherical spreading of the beam from the transmitter to the target $\sigma$, and then again from the target back to the receiver. The fact that the subsurface beam is directive in both radiation planes is accounted for in the antenna gain, which has a maximum of about 5 for an interface antenna radiating vertically downwards into water of refractive index $n=9$. At $50 \mathrm{MHz}$ the attenuation factor $\beta$ is mainly determined by conductivity (or its inverse resistivity) and is approximated for fresh water by the formula

$$
\beta=1 /\left(2 p c \varepsilon_{\mathrm{o}} n\right)
$$

where $\rho$ is water resistivity in $\Omega-\mathrm{m}$, and $\varepsilon_{\mathrm{o}}$ is the permittivity of free space $=8.85 \times 10^{-12} \mathrm{~F} / \mathrm{m}$. A more exact calculation would consider the Debye relaxation of water.

The last three factors in eq A1 were used to compute the transmit/receive footprint sensitivity patterns for two $50-\mathrm{MHz}, 2-\mathrm{m}$-long resistively loaded dipoles separated by $3.7 \mathrm{~m}$ (as used in the studies) with the transmit antenna excited by a unipolar current pulse. The directivity patterns shown in Figure A1 represent sensitivity to nondispersive, isotropically scattering objects along a flat bottom. For the depths considered, the radar patterns differ insignificantly for those for a single transmit/receive antenna. The energy values plotted are the total energy in the pulse waveforms.

Figures Ala and b show that at 10-20 m depth in Lake Sunapee or Pleasant Lake, the received intensity decreases more rapidly with horizontal distances in the E-plane (parallel to the antenna and in the direction of the profiles) than it does in theH-plane, and the sidelobe structure seen earlier for point dipoles is greatly reduced. The narrower E-plane pattern implies that if any of the sub-bottom hyperbolas seen in the records are from off the vertical, they are more likely to have originated from the sides of the boat rather than fore and aft. Figure A1c is for a depth of $10 \mathrm{~m}$ in $100-\Omega-\mathrm{m}$ water and Figure A1d is for the $7-\mathrm{kHz}$ acoustic transducer. The highly absorptive $(1.9 \mathrm{~dB} / \mathrm{m}$ at $50 \mathrm{MHz}) 100-\Omega-\mathrm{m}$ water gives a more narrow radar range footprint in both radiation planes, with the E-plane beamwidth more narrow than that of the acoustic system.

The radar range equation for an infinite flat reflector takes the form given in eq $\mathrm{A} 3$, which does not consider any system losses $(L=1)$.

$$
P_{\mathrm{r}} / P_{\mathrm{t}}=(G \lambda r)^{2} \mathrm{e}^{-4 \beta R} /\left(64 \pi^{2} R^{2}\right)=\left(\mathrm{G}^{2} \lambda^{2} / 4 \pi\right)\left(r^{2}\right)\left(\mathrm{e}^{-4 \beta R}\right)\left(1 / 16 \pi R^{2}\right)
$$

The quantity $r$ is the amplitude reflectivity of the water/bottom interface. The last three terms in parentheses depend on the propagation and were used to compute the propagation losses discussed in the text. 


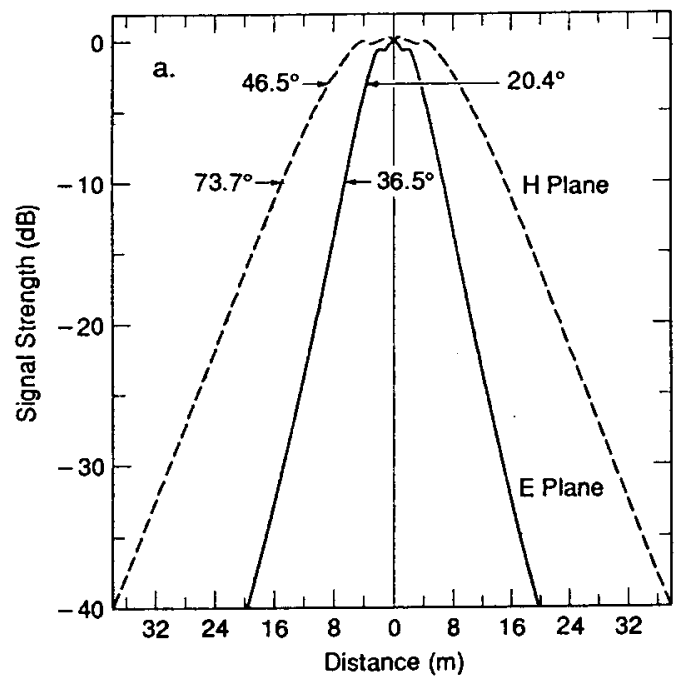

a. 500- $\Omega-m$ water at a depth of $20 m$ and antenna separation of $3.7 \mathrm{~m}$.

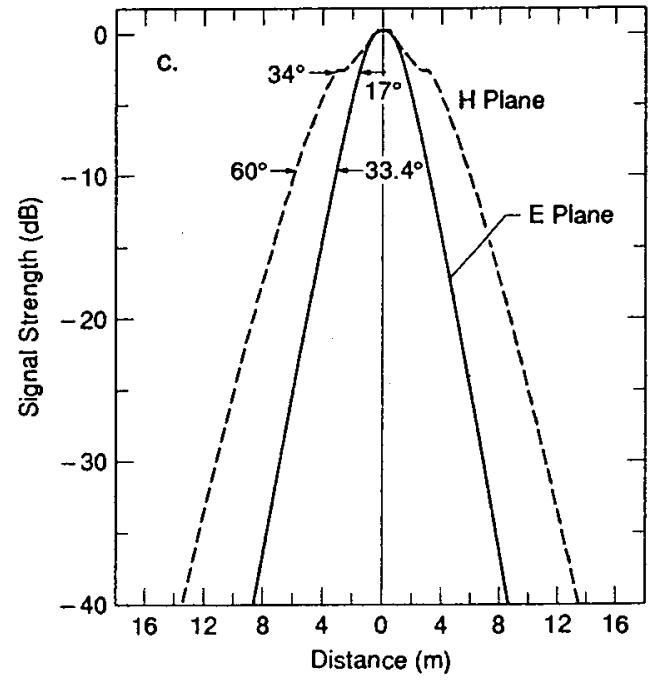

c. 100- $\Omega-m$ water at a depth of $10 m$ and antenna separation of $3.7 \mathrm{~m}$.

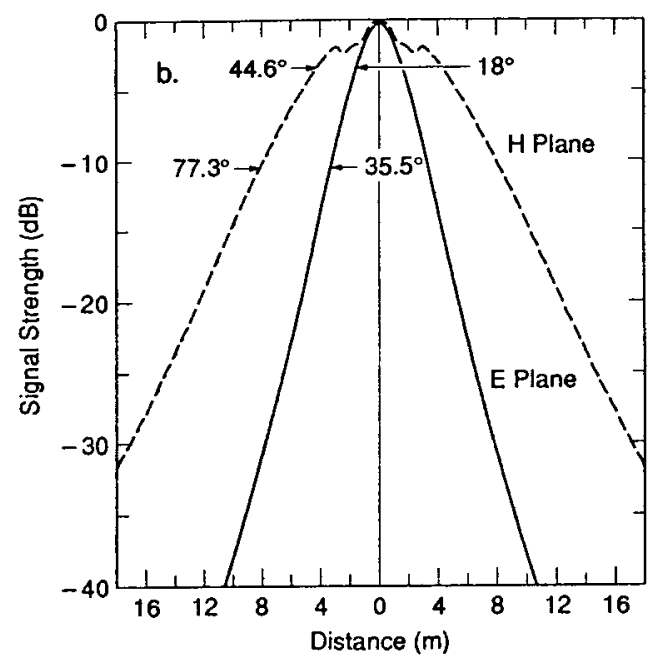

b. Same as Figure A1a, but for $10 \mathrm{~m}$ depth.

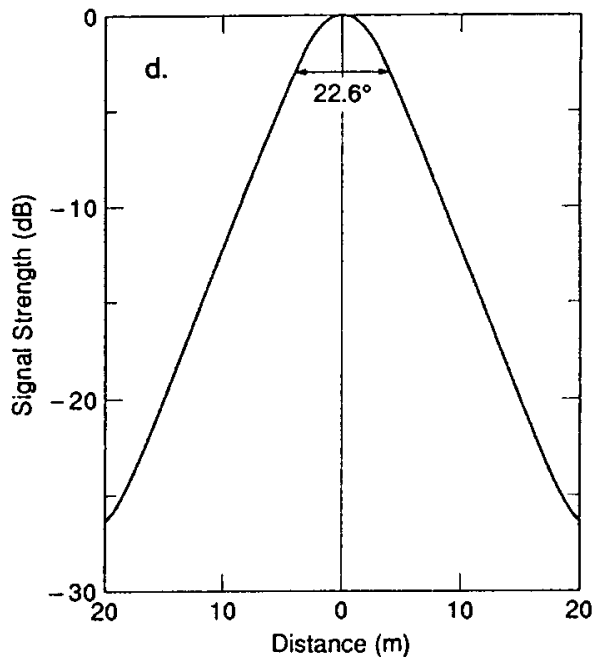

d. 7-kHz acoustic system for a depth of $20 \mathrm{~m}$ and for which absorption losses are considered negligible.

Figure A1. Radar and acoustic (transmit/receive) footprints in the principal radiation planes along the bottom of a lake. The 3-and 10-dB beamwidths are given. 


\section{REPORT DOCUMENTATION PAGE}

Public reporting burden for this collection of intormation is estimated to average 1 hour per response, including the time tor reviewing instructions, searching existing data sources, gathering and maintaining the data needed, and completing and reviewing the collection of intormation. Send commente regerding this burden estimate or any other aspect of this collection of information, including suggestion for rechucing this bunden, to Washington Headquarters Services, Directorate for Information Operations and Reports, 1215 Jefferson Davis Highway, Suite 1204, Arlington, VA 22202-4302, and to the Office of Management and Budget, Paperwork Reduction Project (0704-0188), Washington, DC 20503.

\begin{tabular}{|l|l|l|}
\hline 1. AGENCY USE ONLY (Leave blank) & 2. REPORT DATE & 3. REPORT TYPE AND DATES COVERED
\end{tabular}

4. TITLE AND SUBTITLE

May 1992

Sub-bottom Surveying in Lakes with Ground-Penetrating Radar

6. AUTHORS

Paul V. Sellmann, Allan J. Delaney and Steven A. Arcone

PE: 6.11.02A and

$$
6.27 .84 \mathrm{~A}
$$

PR: 4A161102AT24 and 4A762784AT42

TA: SS and BS

WU: 014 and 011

ILIR and CWIS 32795

7. PERFORMING ORGANIZATION NAME(S) AND ADDRESS(ES)

8. PERFORMING ORGANIZATION REPORT NUMBER

U.S. Army Cold Regions Research and Engineering Laboratory

72 Lyme Road

CRREL Report 92-8

Hanover, New Hampshire 03755-1290

9. SPONSORING/MONITORING AGENCY NAME(S) AND ADDRESS(ES)

10. SPONSORING/MONITORING

AGENCY REPORT NUMBER

Office of the Chief of Engineers

Washington, D.C. 20314-1000

11. SUPPLEMENTARY NOTES

12a. DISTRIBUTION/AVAILABILITY STATEMENT

12b. DISTRIBUTION CODE

Approved for public release; distribution is unlimited.

Available from NTIS, Springfield, Virginia 22161

13. ABSTRACT (Maximum 200 words)

Short-pulse radar was used on lakes in New Hampshire for sub-bottom surveying. The objectives were to construct a low-frequency, high-powered antenna suited for this application, and to evaluate the technique under a range of sub-bottom conditions. A compact $50-\mathrm{MHz}$ antenna with a hydrodynamic housing was fabricated for this study. The transmitter provided a peak input power of approximately $1000 \mathrm{~W}$ and noise was decreased by submerging the separated antennas on each side of a fiberglass boat to assure consistent coupling. A $100-\mathrm{MHz}$ commercial antenna unit placed in the bottom of the boat and a $7-\mathrm{kHz}$ acoustic sounder, both of which had vertical resolution theoretically comparable or superior to that of the $50-\mathrm{MHz}$ radar, and theoretical studies of antenna directivity were used to help evaluate the results. In shallow water of 1-2 m depth, estimates of the thickness of low density organic sediments (1-4 m thick) over more dense bed material were obtained at both radar frequencies. Noticeable apparent sedimentary bedding and layering, various sediment types and variations in the depth to bedrock beneath the bed were obtained in low-conductivity lake water more than $20 \mathrm{~m}$ deep with the higher powered $50-\mathrm{MHz}$ system. Maximum bed penetration was at least $7 \mathrm{~m}$ in these cases and vertical bedding resolution was far superior to the acoustic results. Radar bathymetry and limited sub-bottom data were obtained in water up to $30 \mathrm{~m}$ deep.

14. SUBJECT TERMS

Ground-penetrating radar Radar footprints
Radar performance

Sub-bottom observations

\begin{tabular}{|l|l|l}
\hline $\begin{array}{l}\text { 17. SECURITY CLASSIFICATION } \\
\text { OF REPORT }\end{array}$ & $\begin{array}{l}\text { 18. SECURITY CLASSIFICATION } \\
\text { OF THIS PAGE } \\
\text { UNCLASSIFIED }\end{array}$ & $\begin{array}{l}\text { 19. SECURITY CLASSIFICATION } \\
\text { OF ABSTRACT } \\
\text { UNCLASSIFIED }\end{array}$ \\
\hline
\end{tabular}

NSN 7540-01-280-5500 